SOUND and UNSOUND HORSES, and how to know theme

F. T. BARTON

$$
\text { 5) Neti }
$$




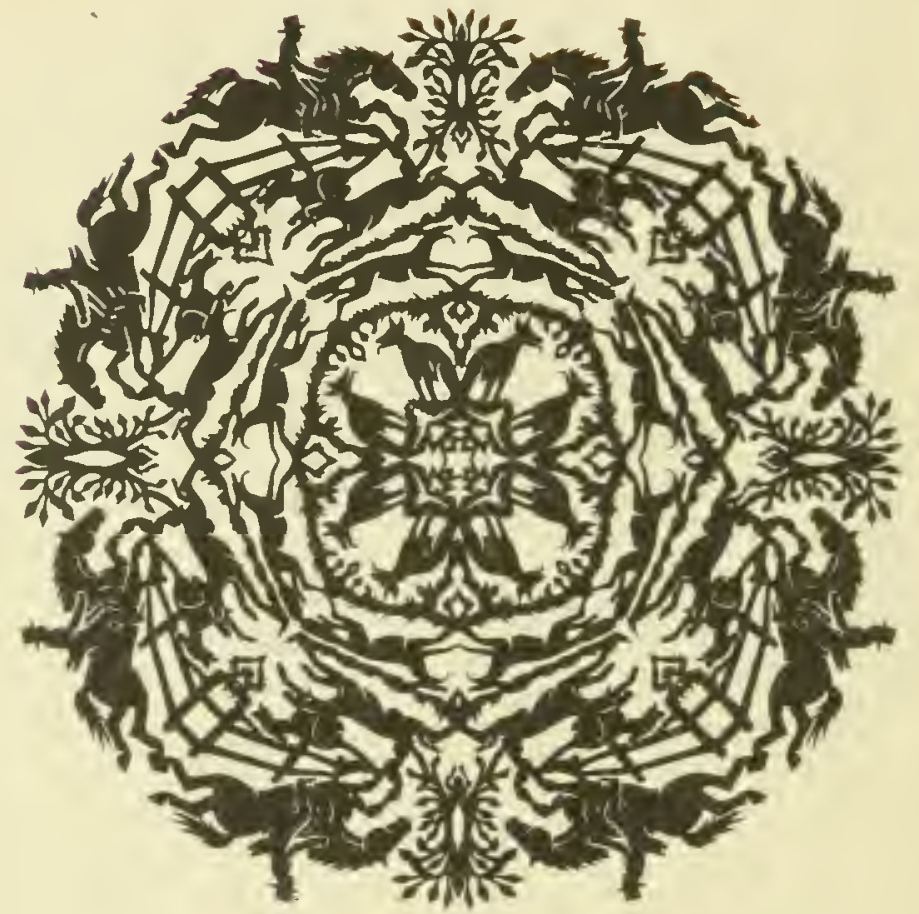

JOHN A.SEAVERNS 


\section{ferir $=25$}

Silfy 5

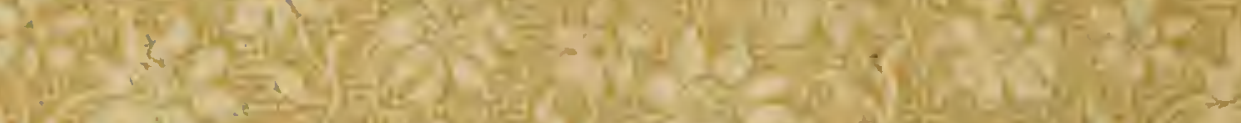

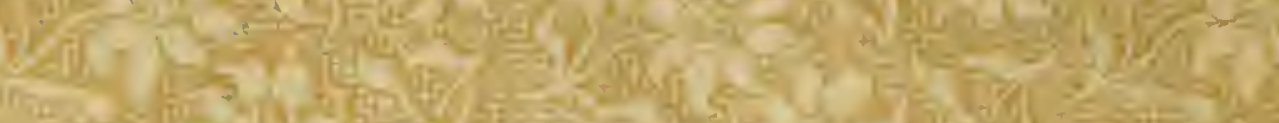

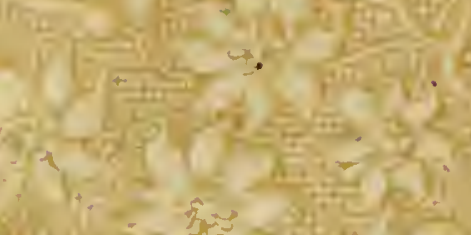

1)

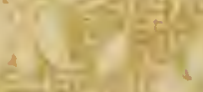

(5i) ing

Coroseng

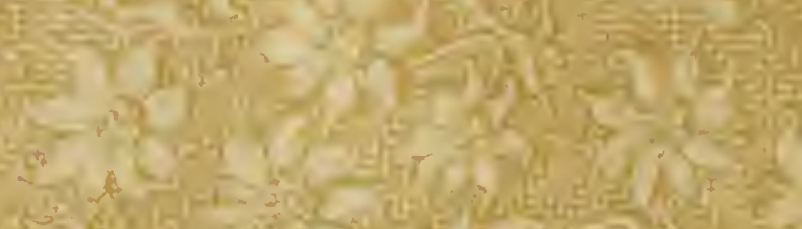

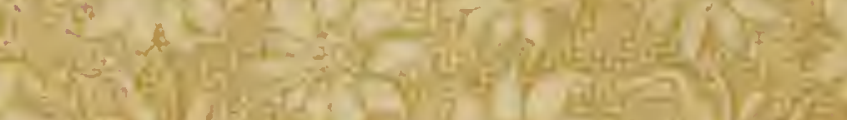
(1)

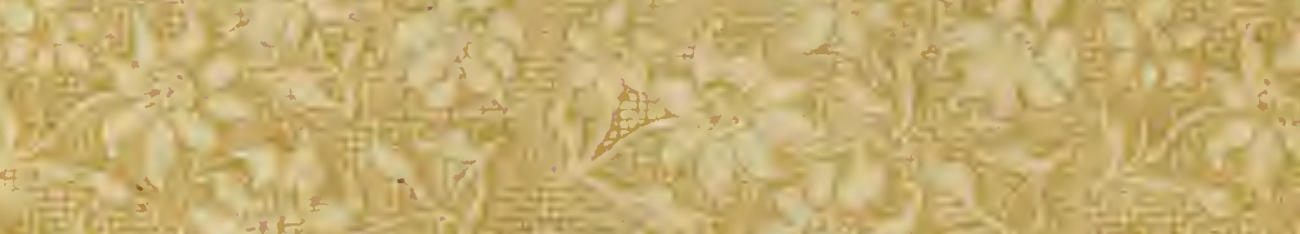

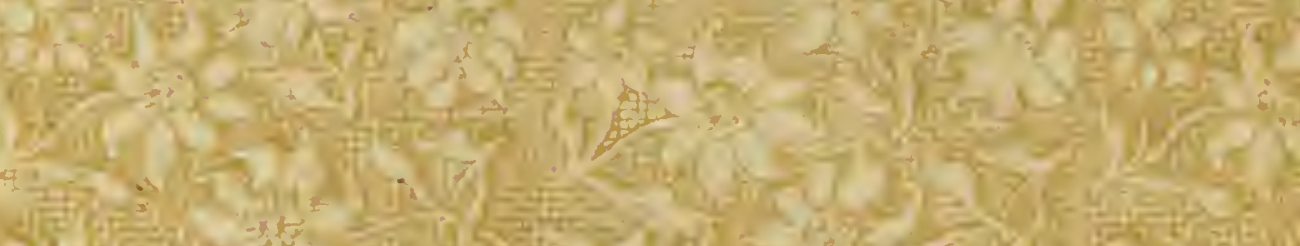

If

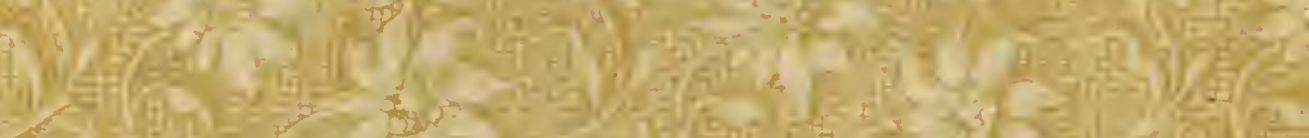

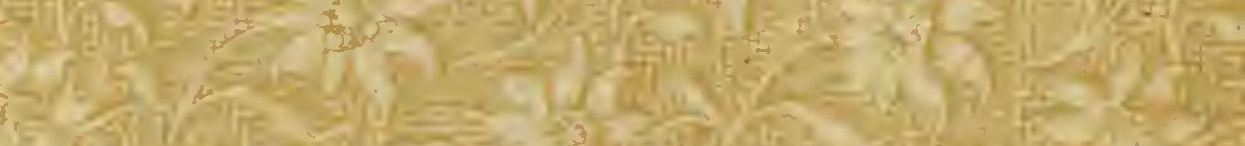
1. Mo by

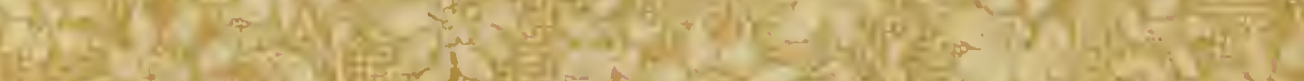
(1) (16)

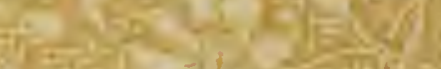

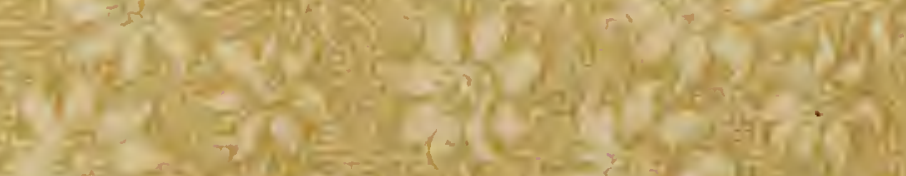
ant

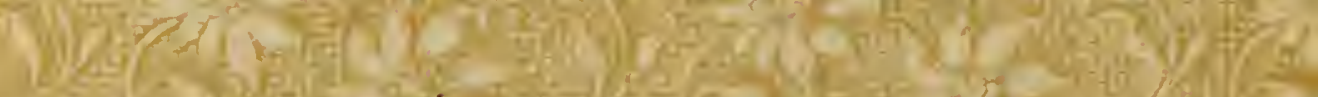

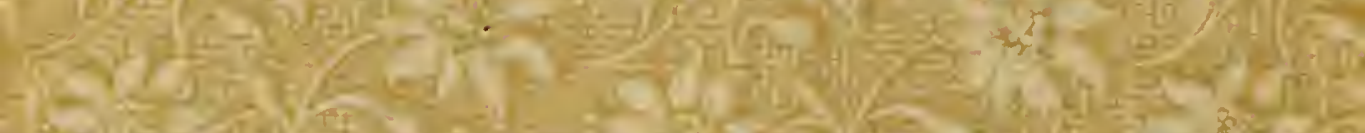

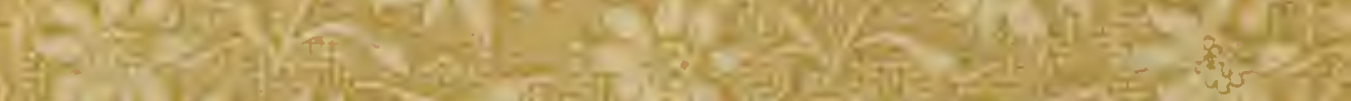

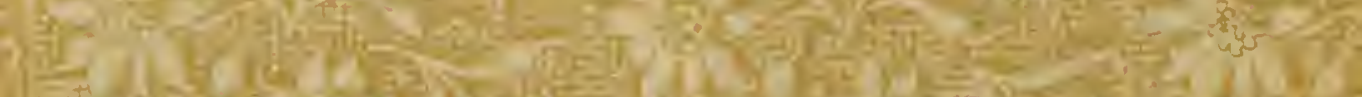
(1) 

SOUND ANI UNSOUND HORSES 


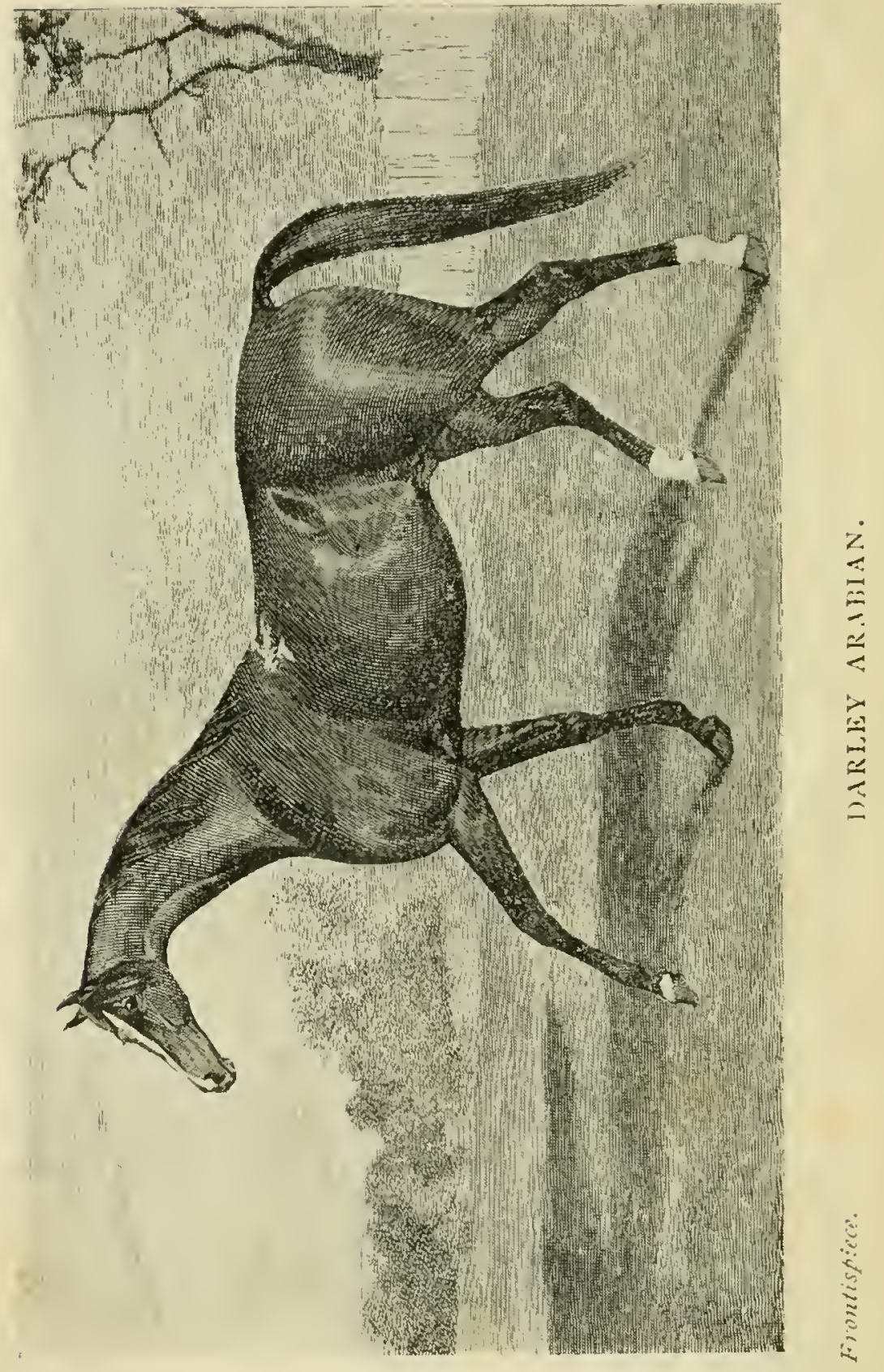




\section{SOUND AND}

\section{UNSOUND HORSES}

BY

FRANK TOWNEND BARTON, M.R.C.V.S.

AUTHOR OF

"Breaking and Training Horses," "The L'eterinary" Manual for Horse Owners," "How to Choose a Horse," "The Gruon's Guide," "Our Frund the HIors"," "The Age of the Horse and How to Tell It," "Diseases and Accidents to the Dog," "Unsound Horses and How to Know" Them," etc., etc.

LONDON

R. A. EVERETT \& CO. (LTD.) 42 ESSEX STREET, STRAND

[All Rights Reseroied] 



\title{
CONTENTS
}

\author{
CHAPTER I
}

\section{OLTLINES OF SYMMETRI' ... IJ}

The Head-The Forehead-Facial and Nasal Regions-The Oral Region-The Cervical RegionDorso-Lumbar Region-The Croup and Haunches - The Caudal Appendage-The Thoracic and Abdominal Regions - Pectoral Limbs-The Shoulder - ElbowThe Fore Arm-Metacarpus-The Fetlock and Paste:n-The Hind Limbs-The Stifle-The Leg and Hock-Tarsus 
VARIETIES OF HORSES AND THEIR POINTS ... ... 39

The Hacliney or Roadster-Saddle and Harness Trotters-Points of the Trotter-Yorkshire Coach Horses, and the Cleveland BayThe Thoroughbred

\section{CHAPTEK III}

$\begin{array}{rrrr}\text { THE HUNTER } & \ldots & \ldots & \ldots \\ \text { Regulations and Rules of the }\end{array}$ Hunters' Improvement SocietyThe Arab-The Parli and Covert Col)

\section{CHAPTER IV}

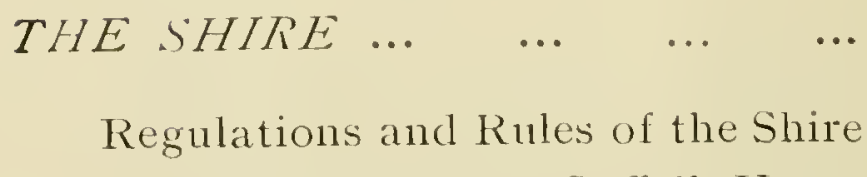

Horse Society-The Suffolk Horse - Regulation of the Suffolk Horse Society-The Clydestale HorseVanners 
IVELSH PONIES $\ldots \quad \ldots \quad \ldots \quad \ldots \quad 92$

Shetland Ponies - Exmoor and

Dartmoor Ponies-Rum Ponies or the Galloway-New Forest Ponies - Connemara Ponies-Polo Ponies

\section{CHAPTER VI}

THE AGE OF THE HORSE ... IO9

Shedding of the Incisor Teeth-Two Years Off-CTwo Years and a Half--Rising Three Years-Three Years-Three Years Off-Three Years and Six Months-Rising liour Years-Four Years and Six Months-Rising Five Years-Five Years Off - Six Years - Seven Iears - Eight Yexrs - TusksMolars-Summary

\section{CHAPTER VII}

DISEASES AND THEIR RELATIONSHIP TO UNSOUNDNESS ... .. $\quad \ldots \quad$ I2

I. Nasal Region.

2. Oral Region. 
3. Facial Region.

4. Sub Maxillary Region.

5. Parotid Region.

6. Ocular Region.

7. Occipital Region.

8. Cervical Region.

9. Dorsal Region.

ıo. Lumbar Region.

I I. Sacral and Iliac Region.

I2. Caudal Region.

13. Scapular Region.

I4. Brachial Region.

15. Anti-Brachial Region.

I6. Carpal Region.

I7. Metacarpal Region.

I8. Phalangeal Region.

19. The Coronet.

20. The Horny Wall-Sidebone-

Indurated Cartilages.

2 I. Solar Region:

22. Costal and Sternal Regions.

23. Abdominal and Inguinal Regions.

24. Gluteal Region.

25. Tibial Region.

26. Tarsal Region.

27. Metatarsal Region.

28. Phalangeal and Pedal Regions.

Chronic Cough-Broken Wind-

Slivering - Stringhalt - Repeated 
Colic-Vertigo-Eczema-MangeIntermittent Pulse-General Unthriftiness.

\section{CHAPTER VIII}

METHODICAL EXAMI.VATION I6

\section{CHAPTER IX}

LAW IN RELATION TO WARRANTY OF HORSES ISS

\section{CHAPTER X}

SALE OF HORSES... _. $\quad \ldots \quad 203$

CHAPTER XI

HORSE SOCIETIES _.. ... 209 



\section{ILLUSTRATIONS}

PAGE:

DARLEY ARABIAN . . . . Firomisticic.

VICTORIA HORSES . $\quad \ldots \quad \ldots \quad \ldots \quad \ldots$

LANDAU HORSES . $\quad \ldots \quad \ldots \quad \ldots$ \& I

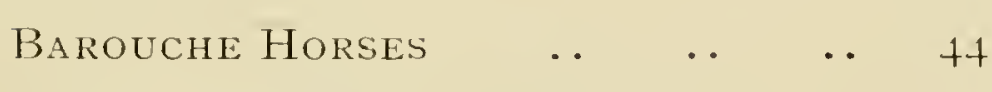

SUFFOLK ENTIRE .

SUFFOLK MARE $\quad \ldots \quad$.

A Tivplcal Shire Hokse $\quad \ldots \quad \ldots \quad 7$ I

Points of the Shike $\quad \ldots \quad$. . . . 74

Shetland POny lintire. . $\quad \ldots \quad$. 99

InCISORS AT TWO MONTHS .. . . I IO

INCISORS AT SIX MONTHS .. , . I I IO

INCISORS OF A YEARLING $\quad \ldots \quad \ldots$ I I I

INCISORS AT TWO YEARS $\quad \ldots \quad \ldots \quad$ I I 2

INCISORS AT THREE YEARS $\quad . \quad \ldots$ I I 5 
INCISORS AT FOUR YeARS $\ldots$. . I 16 InCisors at Five YeARS $\quad . \quad \ldots$ I IS INCISORS AT SIX YEARS . Incisors at Seven Years $\quad . \quad \ldots \quad$ I 20 INCISORS AT EIGHT YEARS .. . I I I 


\section{CHAPTER I \\ OUTLINES OF SYMMETRY}

\section{THE HEAD.}

An inspection of this region may afford one much information as to quality, temper, etc.

\section{THE FOREHEAD.}

In the foal and colt this region is prominent, due to imperfect development of the air spaces within the head. The forehead should be wide and straight.

\section{FACIAL AND NASAL REGIONS.}

The face comprises the region bounded above by the forehead, below 
by the nose, and at the sides, by the eyes, cheeks and nostrils. The face should be wide, a narrow one being a defect. When the nose is convex in its length, the animal is said to be Roman nosed-a common peculiarity in the Clydesdale and the Shire.

The Nostrils should be wide especially in horses required for swift work.

The Ears ought to be fine, short, directed forwards, thin, with a few fine silky hairs in the entry of the passage. The so-called lop-ears are ungraceful, and frequently associated with a sluggish disposition. Biters and kickers often carry their ears pointing backwards.

The Globe of the Eye should be full, well apart from the middle line of the head and free from blemish. The pupil should contract in the presence of light, dilate when a dark object is held 
in front of the eye, or the animal is taken into a darkened apartment.

Freedom from blemishes; long silky eyelashes, a rosy tint of the lining membrane, with frankness of expression, all go to make up the beauty of this region.

The "so-called " wall eye is frequently" met with. Its pearly white colour is due to the absence of pigment in the iris. Only one eve, as a rule, is in this condition. It does not appear to interfere with the sight.

In old horses the fulness of the eye is lost.

The inequality in the size of the eyes is frequently the outcome of disease.

In the myopic eye. the cornea is too convex, whilst the hypermetropiceze is insufficiently so. These conditions render the animal short and long sighted respectively.

The intermaxillary space is triangular in shape, the apex of the triangle being 
formed by the articulation of the jaw in front, lodging the lower incisor teeth, whilst the base is limited by the throat.

The Lymphatic Glands in this region are, in health, small and mobile.

In coarse bred horses, the hairs here are long, stiff, coarse and plentiful.

\section{THE ORAL REGION.}

The mouth demands careful inspection, knowing that so much depends upon the animal's behaviour in response to the " bit" and aids.

$A$ tender mouth is one that responds to the slightest stimulus brought to bear on the bit from the hands. Such a mouth as this may easily become a spoiled one.

The hard mouthed horse is one that requires firm traction upon the bit before it responds to it. It is a very important matter to try the mouth by riding, driving, etc., also make a careful 
inspection of angles and buccal membrane. The lower lip is sometimes paralytic. The bars should be fine, the teeth sound and regular, the tongue entire and firm.

The Parotid region gives better contour to the head when there is a certain amount of depression here.

The position, or " set on " of the head may be either vertical, oblique or horizontal.

In horses used for draught purposes, the first position is a good one.

The horizontal position is an advantage in race horses, though it is not free from objection.

The oblique "set on " head is the best position for general use.

\section{THE CERVICAL REGION.}

The length, depth, direction, carriage and form of neck should all be taken into 
consideration when looking at this region.

For convenience, we may say that the neck has an upper and lower border, two surfaces, an apex and base.

The Apex supports the head, whilst the base is limited by the breast, shoulders, and withers.

Lateral Surfaces should be clothed with thin skin and fue hair, beneath which well developed muscles ought to exist. On this surface, the jugular furrow is seen.

The Upper Border carries the mane. It should be thin.

The Lower Border ought to be thick, round and wide. The windpipe traverses this border, but its relation to the surface differs in different horses.

The so-called Ewe Neck is due to hollowing out of the upper border (concavity) whilst the arched neck arises 
SOUND AND UNSOUND HORSES

through increase of curvature (convexity).

In entire horses this is particularly plain, a pseudo form of it being produced by the bearing rein.

The longer castration is deferred the better the formation of the crest.

The neck may be either too long or too short.

In the Race Horse a long neck is an advantage, but proportionate length in a cart horse would be a disadvantage.

Hackneys, Hunters, etc.. require an intermediate length of neck.

The Mane may be either single or double. The latter is parted in the middle so that the hairs hang both on the right and left side.

In riding horses the mane is turned to the left. By clipping the mane, a practice often done upon ponies, the convexity and sturdy appearance of the neck is apparently increased. In well 
bred horses the mane is fine, silky, without being too full. In inferior horses the hairs are long, coarse and abundant. In Belgian horses the mane is very long, as a rule.

The forelock may be either single or double, coarse or fine.

Coarse Thick Withers are ugly. In trotting horses high withers are desirable, though many fast trotters have low withers. Sharpness is distinctly objectionable, predisposing to galling. Some horses are very ugly in this region, and we remember one that bore a strong resemblance to a bull.

\section{DORSO-LUMBAR REGION.}

At the sides the back is bounded by the ribs, in front by the withers, and behind by the loins.

The back may be long or short.

A short back implies strength, though its degree of flexibility is diminished. 
SOUND AND UNSOUND HORSES

For heavy draught horses it is not objectionable. With increased length of back, there is a corresponding increase in the length of the chest.

The back should never be narrow. Such is commonly associated with flat sides, general unthriftiness, and a defective breathing apparatus.

A straight back is of good confirmation.

\section{A Sway, Hollow or Concave Back} is rather objectionable, resistance being diminished, consequently pace interfered with.

A roach or convex back predisposes to over-reach. In purchasing a hunter or park hack this form of back ought to be particularly avoided.

The loins should be wide and short, especially in saddle horses. Flexibility is all important, any tendency towards anchylosis being highly detrimental, especially in a jumper. 


\section{THE CROUP AND HAUNCHES.}

The croup comprises the region lying between the loins in front, and tail behind, laterally by the thighs and buttocks. The haunches blend with the croup, at the sides, and the angles of the former form the prominences so distinctly visible from behind.

A long croup is desirable, whilst a wide croup is greatly to be desired, especially in brood mares. Narrowness of croup is specially objectionable, not only in a brood mare, but in all classes of horses.

In roadsters, a horizontal croup is preferable, but in heavy breeds, slight obliquity is needful.

If the croup is too oblique, it causes forward deviation of the hind limbs. This is objectionable.

In pregnant mares, the muscles of the croup $\sin \mathrm{k}$ during the latter period of gestation, due to relaxation of the sacroischiatic ligaments. 
Angularity of the croup indicates powerful leverage.

Both the croup and haunches ought to be free from blemishes and muscular atrophy. An atrophic condition in this region is not uncommon after azoturia.

\section{THE CAUDAL APPENDAGE.}

The tail should be well "set on " and nicely carried. If the animal has a croup too oblique, the tail will be badly carried.

The so-called " rat tail " is one having a few straggling hairs upon it, usuaily exposing the stump. As a rule, rat tailed horses are good ones.

It has been stated that the resistance offered, during the forcible clevation of the tail, is a measure of the animal's vigour.

A cryptorchid is one in which the testicle, or testes, have failed to appear 
in the scrotum. It may be unilateral or bilateral.

The evidence of a scar upon each side of the scrotal sac is no guarantee that both testicles have been removed.

In both geldings and entires a gurgling sound is often heard when these animals are trotted, due to the suction action of the sheath. In the mare, the external genital organs should be examined in order to ascertain the absence of diseases or defect.

\section{THE THORACIC AND ABDOMINAL REGIONS.}

The chest in the cart horse ought to be wide, narrowness in this animal being objectionable. Saddle horses, roadsters, etc., ought not to be too open in front. Deep chested horses are often spoken of as being "well hearted."

The ribs ought to be well separated from each other, of proper length and 
curvature, the latter becoming more marked from before backwards. Fatness may render the chest wall " apparently" round. Avoid a horse having short, flat, ill separated ribs.

Rotundity of the chest wall can be seen by looking at the animal from before and behind.

The triple beauties of a well formed chest are found in its height, width and depth.

The abdomen should be in proportion to the size and variety of the horse. A tucked up abdomen indicates a "bad doer."

A pendulous, flat sided belly is distinctly objectionable.

A short flank is desirable, and possessors of such have usually a well developed muscular system. Along with depth of chest, a long flank implies defective conformation. 
Pectoral Limbs. - Scapular, brachial, and anti-brachial regions.

The Shoulder may be either long or short. The former is desirable, even in cart horses. If the shoulder is well clad with muscles then the more oblique it is the better. Obliquity allows greater extension, therefore very necessary in the race horse.

In draught horses a good collar bed is essential.

Full volume of the shoulder muscles in a saddle horse. is objectionable, as the morements would then be hampered.

Freedom from blemishes or wasted muscles is necessary (shoulder-slip).

A moderate length of arm is desirable. If it is too short the forward stride is less. It should be well rounded, full and firm.

The Elbow: ought to be well separated from the sides of the chest. Turning "in " or "out" of the elbows is 
SOUND AND UNSOUND HORSES

distinctly objectionable, causing the toes to be turned "in" or "out" respectively.

The Fore Arm should be long, wide and well placed in animals for speed, though shorter and stouter in cart horses. High action is favoured by a short fore arm.

A slender fore arm constitutes defective energy, probably all round.

The contour of the fore arm in race horses is more or less flattened, but in draught horses it is cylindrical.

In coarse bred horses the chestnuts are much larger than in those of finer breeding.

Sometimes the carpal sheaths are distended through excessive secretion of their lubricating material, causing the appearance of a couple of soft. tumour like swellings behind the joint. This is occasionally spoken of as thoropin of the knee. Sinilar distensions may 
appear in front of the carpus, above it or below it. Freedom from blemishes, thickness, width, are essential points of beauty. The skin covering this region ought to be fine, whilst beneath it there should be no bulky feel (clean knees).

The distance of the knee from the ground necessarily depends upon the length of the radial (fore, arm) and cannon bones. In typical shire horses, the knee is very low down.

Thickness (i.e., width from inner to outer side), gives a stouter support to the body, and diminishes the effects of concussion, consequently renders the animal less liable to splint, etc.

Width or Depth (i.e., front to back), also increases the articulating area, thus giving greater stability.

A plumb line passing from the elbow joint ought to symmetri= cally divide the fore arm, knee, 
cannon, and fetlock, coming to rest just behind the heels.

The terms calf, ox and sheep knee, are applied to this region when it is defective in width, deviates inwards, or is situated behind the vertical axis, respectively. All are objectionable. Deviation of the knee inwards causes the toes to point outwards, whereas outward deviation inclines the toes inwards, in this manner predisposing to brushing, etc.

Metacarpus.-Many cart horses feel far too bulky in this region, indicating a sluggish temperament. Bone and tendon only should be felt.

In race horses the cannon ought to be long, but not too fine.

In most horses the cannon should be short, fine, thick.

The Fetlock and Pastern.-The fetlock should be wide, clean, have a proper slope, and be covered by thin 
skin. An upright fetlock, or one too oblique, is strongly objectionable in any breed of horse. In certain breeds (Clydesdales and Shires, etc.), there ought to be an abundance of long and silky hair extending up the back of the cannon. There should be freedom from bruising, etc.

The horny growth at the back of the fetlock is known as the ergot, and the tuft of hair, the footlock.

Small, thin, or weak fetlocks are objectionable.

No matter whatever the variety of the horse, width is highly desirable.

Moderate length of pastern, width and thickness are the chief points to be looked for in this region.

A pastern too long or short is decidedly defective. As a rule, these defects are rendered more so by excessive obliquity and uprightness in accordance with the length or shortness of the bone. Clip- 
ping the hair off this region in the lighter breeds produces a degree of neatness, and is often the means of disguising an otherwise coarse bred animal.

At the same time the hairs around the coronet are usually clipped off.

A iypical foot should have a strong, well developed elastic foot pad, so that when the foot is upon the ground it roill rest upon this. The sole must be concave and firm, with bars plainly marked; the horn of the wall bluishgrey or perfectly free from brittleness, cracking, or indentation, together with fineness of its fibrous material.

The heels should be well apart, and their height equal to one half of that at the toe. The average degree of inclination at the toe of the fore foot is fifty degrees, whilst it is about twelre degrees more in the hind.

The volume of the foot must be in proportion to the size of the animal. It is 
a very common matter to observe an otherwise good horse, with feet scarcely worthy of the name. Nothing could be more objectionable than a Shire or Clydesdale horse with small feet. Many roadsters have feet quite out of proportion.

Hard, soft, or brittle horn; high heels; low heels; shrunken foot pad; flatness of sole; pumiced foot; contracted heels ; turning "in" or "out" of toes; inequality in size; are all faulty.

The Hind Limbs. - The muscles in the region of the thighs and buttocks are mostly large and powerful.

The thigh and buttock (quarters). The portion of the thigh nearest the stifle ought to be well away, though not too far, from the sides of the belly and flank, otherwise progression is hampered.

Moderate obliquity and length are the essentials of beauty in this region. If 
the thigh is short, it makes the buttock look too plump. Another very important matter is width and thickness. The first implies measurement across and beneath the hip joint, whilst thickness is judged from a back view. Care must be taken not to be misled by mere rotundity of buttocks, probably most of which is fat. Sound muscular development is not difficult to tell.

Flatness, inequality, or blemishing are to be looked for when purchasing.

The Stifle.-Here, freedom of movement and absence of wasted muscles is necessary. In colts, particular care must be devoted to this region, as youth no doubt renders them predisposed to laxation.

The Leg and Hock. - The leg extends between the stifle and hock. Its long part consists of the tibia and fibula.

The length of the leg is equal to that of 


\section{SOUND AND UNSOLND HORSES}

the fore arm. It should be long-indeed, cannot scarcely be too long, whenever speed is required. A long leg enables the animal to get over the ground quickly. Trotting horses and thoroughbreds ought to be long in the leg. In horses for slow work the length is less important. The camnon should be proportionate in length.

If the leg is too straight, the lower portions of the member are brought too much under the body. Such a defect is indicated by saying that the animal is under itself behind.

If the leg be too oblique, it makes the horse "camped."

\section{TARSUS.}

In the selection of a horse, the hock demands primary attention, being a common seat of disease, whilst peculiarity of conformation predisposes towards the production of such. 
The hock has four suriaces, viz., front and back (anterior and posterior), inner and outer.

The front face is often termed the fold of the hock. The tendons of the flexor metatarsi and extensor of the phalanges comes over it, whilst the saphena vein (the distension of this constitutes the so-called blood spavin) crosses it obliquely.

The hind face shows the point of the hock.

Inner Face.-This is convex in front. Three small bony eminences are present upon it. The first of these is in the middle, and almost on a level with the point of the hock. The second one is lower down and a little behind it, whilst the third projection is a little further backwards, but just where the camnon begins. It is on this face that a portion of the lubricating membrane of the joint is unsup- 
ported, hence the liability to fill up and bulge.

The Outer Face.- Just about the level of the point of the hock, and on tre outer side, there is a depression. This is the hollow of the hock. This surface undulates. The first "rise" is due to the external tuberosity (projection) of the tibia; the second one to the base of the os calcis; and the third, to the head outer splint bone.

A typical hock should be wide, clean (neat in outline), thick, open, and well directed.

The so-called "tied in" hock is narrow at its base, and is believed to predispose to spavin.

Lean hocks are indicative of beauty. In these the skin is thin and its tenuity allows the bony eminences to be plainly seen in outline.

By the width of the hock we mean the distance from the "point" to the 
"fold," whilst its thickness is measured from the "inner" to the "outer" side.

If the camon inclines obliquely forward. it causes the hock to be over-bent or sickle (scythe) shaped, and this is a predisposing factor in the production of Curb.

The hock should be parallel to the median plane of the body.

When the points of the locks approach each other, as in the cow, the horse is termed cow hocked.

Excessive divergence, on the other hand, causes the animal to be bow legged and its toes inclined inwards.

In order to determine the correct position of the hind limb, in relation to that of the body, a plumb line held at the hip joint, should pass through the middle of the leg, coming to rest at the middle of the hoof, remaining an equal distance from lines which pass 


\section{SOUND AND UNSOUND HORSES}

from the stifle joint and upper part of the buttock respectively.

In a camped horse the line will fall a considerable distance in front of the toe, whilst in one in which the limbs are too much under the belly, the line will fall behind the limb, perhaps just touch the point of the hock. 


\section{CHAPTER I}

\section{VARIETIES OF HORSES AND THEIR POINTS}

\section{THE HACKNEY OR ROADSTER}

MORE particularly during the last few years this variety of horse has become exceedingly popular, and some very fine specimens are seen at the Annual Show in London, likewise whenever a suitable classification is offered by an Agricultural Society. It is, and deservedly so, a very popular class of horse, constituting the best form of animal for victoria, brougham, landau 
or barouche purposes, likewise equally stylish and useful in single harness.

It has been said that a "hack" is a horse to ride, but a "hackney" is one

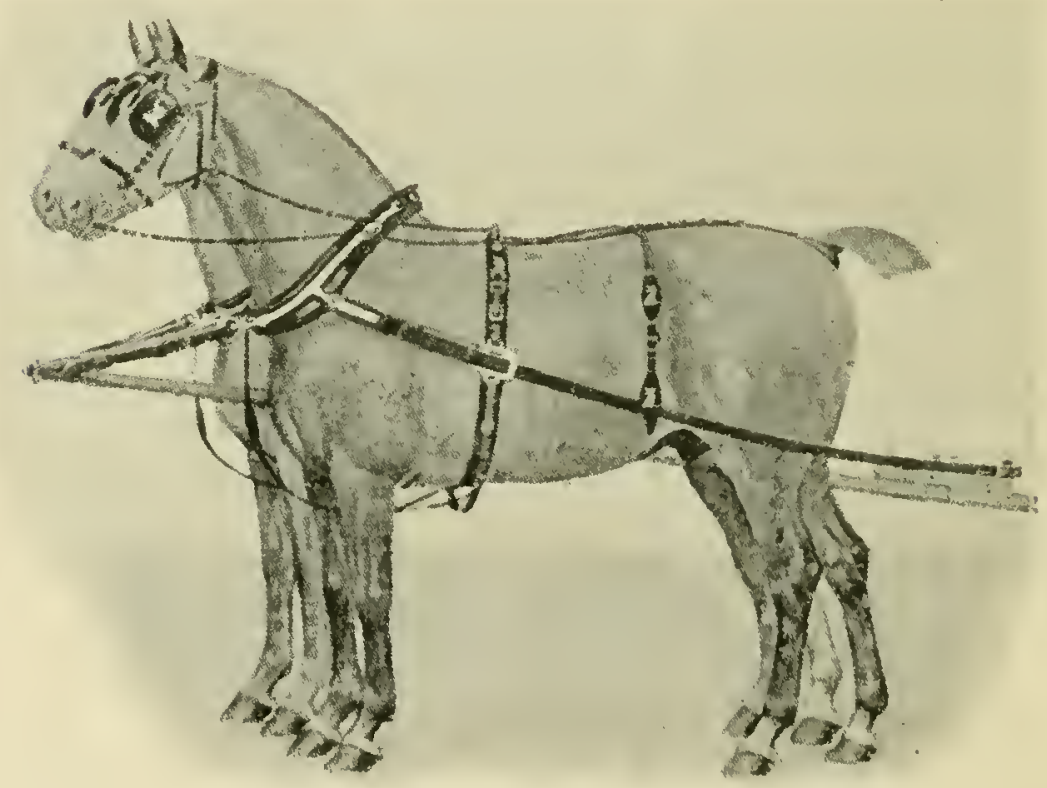

VICTORIA HORSES.

that you should not ride. So far this may be true; nevertheless, the writer has known plenty of hackneys first class saddle horses. 
SOUND AND UNSOUND HORSES

The hackney of the present day is unquestionably somewhat bigger than that of the past era, when he passed under the title of "Norfolk Trotter."

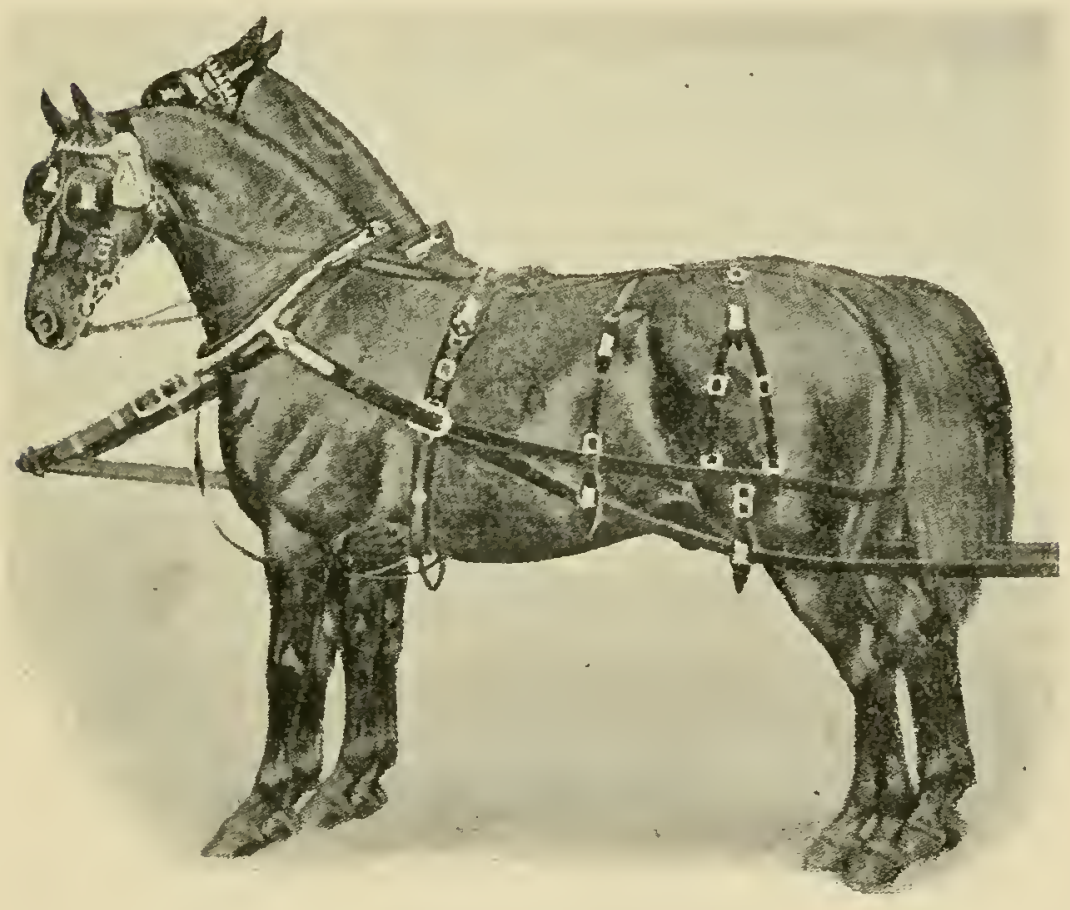

LANDAU HORSES.

Before the reign of good Queen Anne, this animal was praised for his activity. and surefootedness. Continental de- 
SOUND AND UNSOUND HORSES

mand for the hackney robbed this country of animals that it could ill afford to spare, but the alien purchasers knew what they were about, obviously much more so than the Home Government.

Representatives of foreign Governments purchased these hackney sires to put to mares for breeding artillery horses, and, it is said, with the most satisfactory results.

For breeding harness horses the hackney sire has no equal, as by proper selection of mares, the best of carriage horses can be bred, in which action, staying power, manners and style are the chief requirements. In tracing the origin of the hackney, the foundation stone was laid during the reign of King Charles, by the importation of three Eastern sires, as follows :-

Byerley Turk, imported in 1698 .

The Darley Arabian, imported in I706. 
SOUND AND UNSOUND HORSES

The Godolphin Arabian, imported in I730.

It is said that the hackney sires of the present day are descendants of the Darley Arabian.

One of the most famous hackney sires of recent times was Danegelt (died I 894) a direct descendant of the Arabian imported by Mr. Darley.

To illustrate this we give the male pedigree of the famous sire :- -

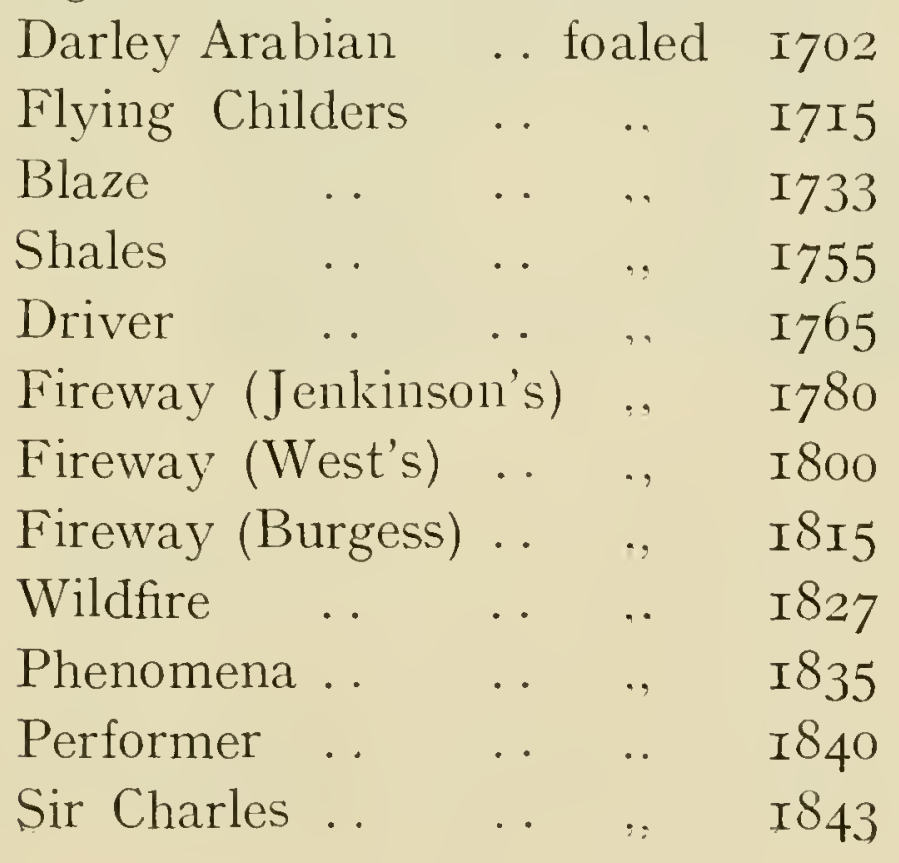


SOUND AND UNSOUND HORSES

Denmark .. . . foaled IS62

Danegelt .. ... ,, IS79

Through the last named hackney sire this illustrious line is preserved.

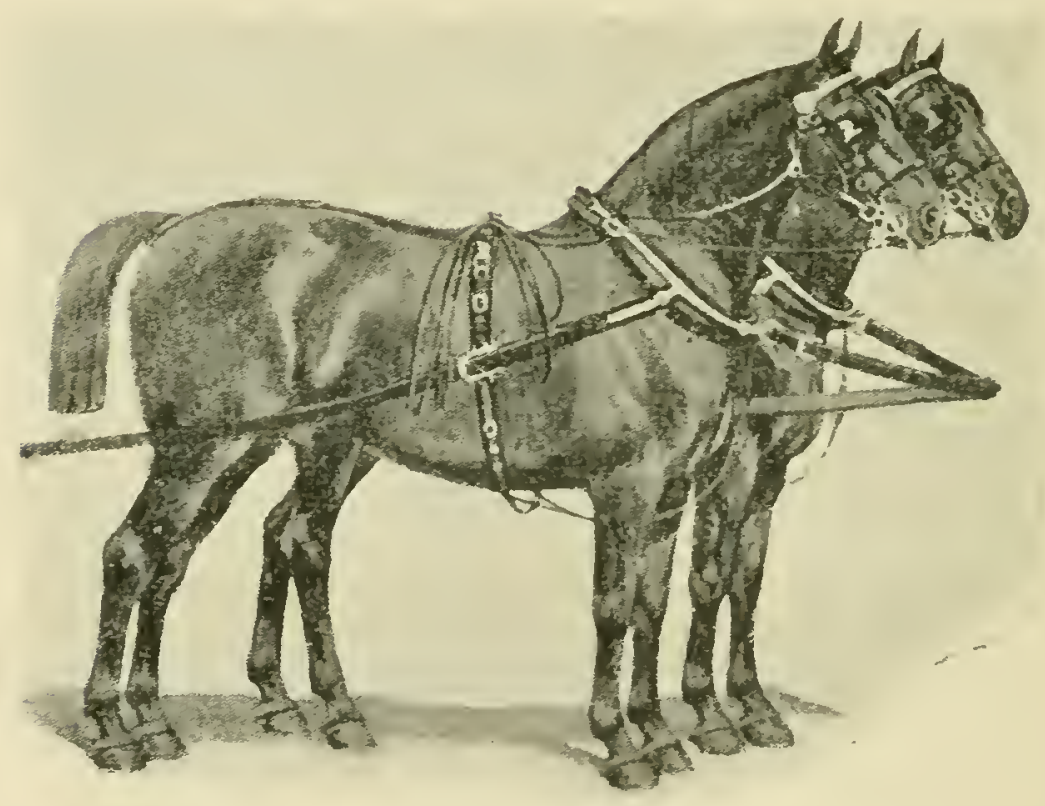

BAROUCHE HORSES.

\section{POINTS OF THE HACKNEY.}

General Appearance.-A stoutly built, compact. high couraged, medium sized horse, with legs and feet in pro. 
portion, and when at rest, symmetry of all parts; quick and active when walking, and showy and fast at the trot.

\section{'THE HEAD.}

This should be of medium size, free from coarseness or heaviness, and neither carried too high or too low.

The Eyes full and placed well apart.

Ears small, fine, and well pointed.

The Neck should be gracefully curved, of medium length, and free from any tendency to weediness.

It should have a beautiful descent towards the shoulders, which ought to be of moderate length and strongly clad with muscle.

Fore Arms long and cannon bone proportionate.

Knees broad and covered by thin skin, with a corresponding condition of the hocks, which should be clean and 


\section{SOUND AND UNSOUND HORSES}

free from any puffy feel. Coarse and over-bent hocks are decidedly objectionable.

It is said that a good horse may be any colour, a statement that is not inapplicable to the hackney.

Probably the most popular colours are chestnut and bay, either light or clark. Many hackneys have white points, to which some buyers object. The latter also applies to light chestnut horses having the so-called "mealy" legs.

In height, i5 to I6 hands, but barouche horses require to be up to as much as $I 7$ hands. A good height for landau horses is I5.3 to I6.I; victoria horses, I5 to $\mathrm{I}_{5.2}$ or $\mathrm{I5.3}$ : barouche horses, I6.2 to I7 hands.

For a good general trapper, such as one to suit a professional man for visiting and running in a gig, the height should be about Ij.I or I5.2. 


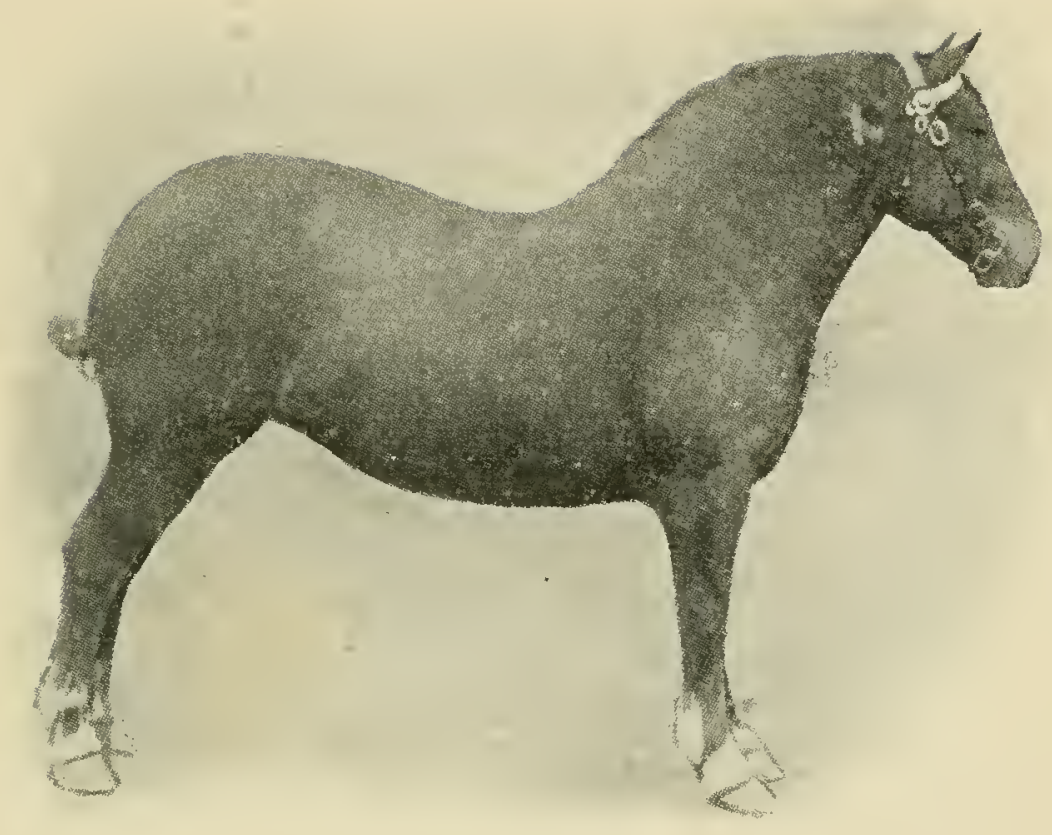

SUFFOLI MARE.

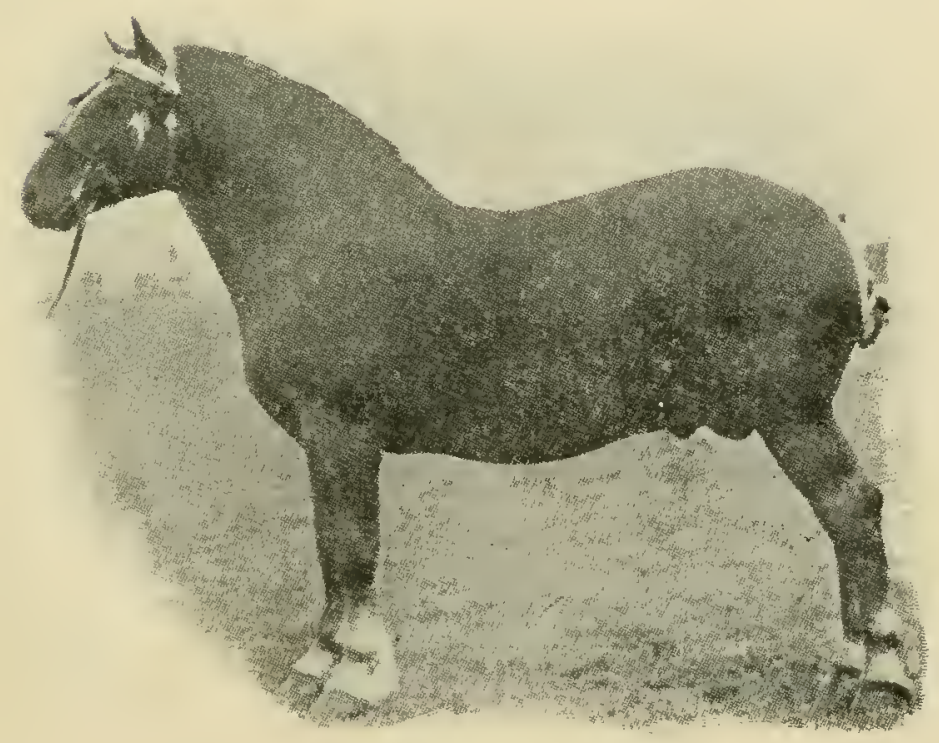

SUFFOLK ENTIRE. 


\section{SADDLE AND HARNESS TROTTERS.}

Trotting is a very popular pastime and one that creates a lively interest not only to those who are fortunate enough to possess really good animals, but to such as make it a point to attend the best meetings.

No matter however good a trotter may be in other respects, if he has not a high degree of speed and staying power, he will never make his mark on the track.

\section{POINTS OF THE TROTTER.}

General Appearance.-As a class these horses differ greatly, some being handsome, well knit horses, others very far from approaching beauty in conformation.

Certain anatomical features must be present, giving the animal the appearance 
of being a long backed, high withered, long legged, slack looking horse.

The trotter is anything but a "compact" animal, a conformation which would be against him.

The average height is about 15.2 , but some are 16 hands or thereabouts.

The Neck should be long, so should the shoulders and fore arms, likewise have a powerfully developed muscular system clothing them.

Some trotters are very high in the withers, others not so.

Powerful Quarters, a long straight back-hollow for saddle trotting-with strong knee, hock, and fetlock joints, in which flexion and extension ought to exist in the highest state of perfection.

The slightest stiffness in these regions is very detrimental to this class of horse.

Every joint should work as if moved by electricity, and in perfect harmony. 
SOUND AND UNSOUND HORSES

As regards colour, the old axiom that a good horse may be any colour, is never more applicable than with reference to the trotter.

\section{YORKSHIRE COACH HORSES, AND CLEVELAND BAY.}

\section{YORKSHIRE COACH HORSE.}

Compared with the past, coach or post horses are in small demand, consequently there is little stimulus for breeders to produce this class of animal.

The old Yorkshire coach horse was made of the right material for long journeys, often under the most adverse conditions as to weather, etc.

In height he was from I5.3 to $16 \frac{1}{2}$ hands or thereabouts, bay or brown, with black points. Although distinct from the Cleveland bay, the Yorkshire coach horse was the result of crossing the Cleveland with a thoroughbred. 
Most of these horses were bred in the East Riding of Yorkshire.

In build and general appearances the old Yorkshire coach horse was a big, powerful animal, having long quarters and strong loins, a well arched neck and deep shoulders. Strong joints and broad cannon bones are essentials in this class of horse.

The coach horse of to-day is somewhat lighter built, in accordance with present requirements.

\section{THE CLEVELAND BAY.}

Typical specimens of this variety of horse are not common, more especially away from their native locality-Cleveland, Yorks, and to some extent in adjacent counties.

There is no difficulty in recognising these horses, a remarkable characteristic being found by the manner in which the 
tail is set on, its graceful carriage, and the beauty of the hind quarters.

The only horse that resembles it in this respect is that used by blackmasters, i.e., the Belgian, and even in this horse there is considerable distinction between them.

Body of medium size, limbs rather long, but proportionate. In height the Cleveland is about I 6 hands, bay, with black points.

General Appearance.-The breed reminds one of a stoutly built Eastern horse, and it is quite, indeed more than likely, that Oriental blood has been the foundation stone of the Cleveland.

These horses are capital workers; as a rule good-tempered, and particularly suitable for the lighter work of a farm, for mineral water carts, and other forms of van work. They are not heavy enough to suit the heavier vans used by railway contractors, etc. 


\section{THE THOROUGHBRED.}

The head should be long, and the forehead straight, covered by thin skin, shewing the various bony prominences in outline. Nostrils wide, and eyes placed well apart.

The neck must be long, narrow at the "set on of head," sloping down to deep shoulders, loins strong and chest deep.

Length of fore arm and length of leg are absolutely essential.

Back ribs, inclined to be short, yet depth of girth.

Knees, hocks, and fetlock joints, broad, and free from disease.

Pasterns long, but not too oblique.

The flexor tendons should be firm, yet fine withal, and the action free and graceful, with long, light, elastic strides.

Colour : brown, chestnut, bay, etc.

Height, I5, I5 $\frac{1}{\underline{z}}$ or 16 hands. 


\section{CHAPTER III}

\section{THE HUNTER.}

\section{The Hunters' Improvement Society}

has done much towards the encouragement of breeding, and the introduction of premiums to Thoroughbred sires for hunter stock-getting purposes. To establish a race of Hunter sires, seems to be the correct method of solving the chance production of "weight carrying" animals.

The aim of the foregoing Society is not that of discouraging the use of thoroughbred blood in the Hunter, but the production of more stable sources 
SOUND AND UNSOUND HORSES

for the supply of weight carrying animals, so difficult to procure.

As a sire, it is an undisputed fact that the Thoroughbred is unequalled for getting Hunters, the chief drawback being that the small mares are apt to produce "light weight" carriers.

If the mare is small, the would-be weight carrier breeder must endeavour to find a big Thoroughbred sire : even then, disappointment may be the result.

For hunting purposes, a stoutly built Thoroughbred has no superior. The chief difficulty of obtaining this class of horse as Hunters, is owing to their incapacity to carry " heavy weights," and as weight carrying Hunters are in such great demand, heavy weight riders find it difficult to purchase horses of the Thoroughbred stamp, for this purpose.

The neck must be long, but free from arching. 
Ears, erect, and well open,

The loins ought to be strong, broad, and free from the slightest degree of stiffness.

Withers rather prominent, yet not too high.

The chest should be deep and broad.

Freedom of shoulder movements is one of the most important points about the Hunter's action.

In addition to perfect shoulders, powerful thighs and quarters are necessary. The body must denote strength and compactness.

A light head, and broad joints, are equally important.

Another very necessary matter in the conformation of the Hunter is that the fore limbs be well placed in relation to the body, and that the feet turn neither in nor outwards, but point fair to the front.

Perfection in hock and shoulder

$$
5^{6}
$$


action are imperative, and to be a good Hunter, the animal should freely bend himself. Bending lessons are useful in schooling a Hunter.

Defective impulsion, or diminished flexibility of the hind limbs, are the chief causes of not clearing the object. Disease of the hocks is not an uncommon cause of this fault.

Chestnut, bay and grey are admired.

Brown is a favourite colour with some, but it is purely a matter of taste.

A Hunter should be in its prime at six years. A five year old is preferred by many.

Those who are beginning hunting should buy an animal that is thoroughly schooled to the work, i.e., a finished Hunter. A Hunter at from eight to twelve years of age, or even older, would be far more likely to suit a beginner, provided that the animal is sound in wind, limb and sight. 
Height, average from I5.2 to I6 hands.

Trial: Before completing the purchase of a Hunter, it is distinctly advisable to jump the horse in cold blood, and then with the hounds.

A born Hunter should be equally good in both places.

\section{REGULATIONS AND RULES}

OF

\section{THE HUNTERS' IMPROVEMENT SOCIETY,}

12, Hanover Square, London, W. HUNTER STUD BOOK.-Vol. I.

Under the rules adopted by the Members at the Igo2 Annual General Meeting, the Hunter Stud Book is divided into two sections, to be termed "STud Book" and "Supplement."

I. The Stud Book to include Stallions and Mares and Fillies. 
SOUND AND UNSOUND HORSES

2. The Supplement to include Mares and Fillies, winners of prizes and medals at National County and Associated Shows, and inspected.

Separate Forms are provided for each Section, viz. :-

I. Stud Book_-Stallions (white).

2. Stud Book-Mares and Fillies (green).

3. Supplement-Mares and Fillies (pink).

\section{I.-STUD BOOK.-STALLIONS.}

A Stallion, two years old or upwards, by a Thoroughbred or Registered Hunter Sire, and out of a Dam registered in Vol. I of the Stud Book, shall be eligible for registration, provided a certificate of soundness, signed, by a qualified Veterinary Surgeon, approved by the Society, is lodged with the entry, and provided such Stallion is jointly 
inspected and approved by a Member of the Council, appointed by the Editing Committee, and a Member of the Society nominated by him.

Fees (to coyer all inspection expenses) per entry :-Members, 10s.; Non-members, £1.

\section{2.-STUD BOOK.-MARES AND FILLIES.}

A Mare, yearling, or upwards, shall be eligible for registration in the Stud Book (a) Provided she has two direct crosses of Thoroughbred or Registered Hunter Blood, viz., Sire and Dam's Sire, or

(b) Provided her sire is a Thoroughbred or Registered Hunter Sire, and her dam a Mare registered in Vol. 1. of the Stud Book ; or

(c) Provided her Produce have won races under Jockey Club or National Hunt Rules, and she is inspected and approved by a Nember of the Council, ap- 
SOUND AND UNSOUND HORSES

pointed by the Editing Committee, and a Member of the Society nominated by him.

Under $(a)$ the correctness of the Breeding must be certified by the Breeder of the Mare, and by the Breeder of the Dam, who shall also give colour and age of the latter Mare.

Under $(b)$ the Breeder must certify as to the correctness of the pedigree.

Fees per entry:-Members, 2s. 6d.; Monmemoers, $5 \mathrm{~s}$.

\section{3.-SUPPLEMENT.- MARES AND FILLIES.}

A Mare, yearling or upwards, shall be eligible for entry in the Supplement

(a) Provided she is by a Thoroughbred or Registered Hunter Sire, and is awarded one of the Society's Gold Medals at National, County or Associated Shows; or 
SOUND AND UNSOUND HORSES

(b) Provided her Sire being a Thoroughbred or Registered Hunter Sire, she wins, or breeds a winner of, a prize at a National, County or Associated Show; or

(c) Provided she is inspected and approved by a Member of the Council, appointed by the Editing Committee, and a Member of the Society nominated by him, a certificate of soundness by a qualified Veterinary Surgeon, approved by the Society, being lodged with her entry.

Note.-No numbers will be allotted to Mares in the Supplement, an entry in the same being recorded by the letters (Supp., Vol. I.) following the names.

ProducE.-Colts bred from Mares in the Supplement will not be eligible for registration and number in the Hunter Stucl Book. Fillies only will be regis- 
tered in the Stud Book if they comply with the Rules of same.

Fees per entry (to cover all expenses for inspection) :-Members, 5s.; Non-membe:s, $10 \mathrm{~s}$.

\section{THE ARAB.}

About two centuries since three famous Arabian Sires were imported, and their names deserve to be known by every horseman, seeing that most of the Thoroughbreds and Hackneys of to-day have descended from one or other of those illustrious sires.

The names of those horses are, Byerly Turk, Godolphin Arabian, and Darley Arabian.

The debt of gratitude due to these importers of the past, by this and other countries, cannot be painted in words, but their memory will ever be with us so long as the beautiful equine specimens of the race-course and road exist. 
In colour, the Arabian varies; some are white, others cream, chestnut, brown, black, or black and white, etc.

For staying power and endurance upon scanty rations, the Arab has a notoriety second to none. There is something very striking about his conformation, and that is chiefly in connection with his hind quarters and set on of tail, the last named being set on " high up," and exquisitely carried.

The head is long, narrow and straight, joining a long, but gracefully curved neck.

Long fore arms and cannons, strong loins and quarters, with deep chest and shoulders.

"Clean" jointed, and springy action.

The back ribs rather short, yet plenty of depth at the girthing place.

Fine hair, thin skin, small erect pointed ears, and a facial expression indicative of the highest degree of equine 
intelligence, are all found in the typical Arabian.

The walk of these animals is best described as "stately," for such it truly is.

\section{THE PARK AND COVERT COB.}

As the name implies, the former is used in town and the latter in the country, and the necessity for smartness is not so necessary in the latter as in the former.

From I4 to 15 hands, - certainly not above 15.2 -is the right height for a cob; anything beyond or below ought not to come under this category.

When selecting a cob for roadster purposes, it is advisable to try and find one, having fairly high, good all round action.

Many horses have good fore leg action but very little behind, which is equally, or even more, important. 
For saddle purposes, high action is not wanted, if comfort to the rider be studied.

A slightly flat side is also better for saddle purposes, whereas in a roadster cob, the ribs should be well sprung.

Short legs, a short arched neck, with nicely sloping shoulders, broad and flat knees, rounded cannons, moderately long, oblique pasterns, with neat, well placed and well directed feet, are essentials. Of no less importance is a light fore hand.

The knees ought to be broad, neatly shaped, flat at the front and free from scars or other blemishes.

The head should be carried obliquely, finely modelled-not the heavy headed brute so often seen-and a mouth that responds immediately when asked. A deep chest and clean hocks covered by thin skin are requisite.

The cannons should be seen as skin, 
bone and tendon, without any packing, and free from puffiness about the joints.

Colour : This is a matter of individual taste. Bay, brown, light or dark chestnut, red, and blue-roan, white, grey, etc.

A typical cob should look smart, graceful. and full of animation, associated with the best of manners.

With reference to the breeding of colts of this description, the best results are probable if a small thoroughbred sire be put to a small hackney mare.

Weight carrying cobs (up to fifteen stone), are not always easy to find, moreover, there is a ready market for good ones.

Orkney cobs are as a rule stoutly built, and large numbers are imported into Aberdeenshire.

These animals are somewhat coarse, but generally good tempered, and not 


\section{SOUND AND UNSOUND HORSES}

at all unsuitable for covert cobs, having the advantage of being purchasable at small prices.

Russian cobs come to this country by the ship load. They are extremely hardy, have not much appearance, but if properly broken make serviceable roadsters for tradesmen's work. 


\section{CHAPTER IV}

\section{THE SHIRE.}

THERE is no more popular and useful variety of horse than the Shire, and whenever a heavy weight has to be drawn, the services of these animals are in demand.

For several generations the Shire has existed as a distinct type of horse, and as the name implies, the land of his nativity was in the Shires, such as Warwickshire, Lincolnshire, Derbyshire, Leicestershire, Yorkshire, etc.

Just in the same manner that the modern thoroughbred and hackney owe 
their existence to the Darley (or other two) Arabians, so does the Shire trace his history to an animal called the Packington Blind Horse, the services of this horse apparently being in great demand amongst the Shire farmers about I755, descendants of this horse being Kirby, Old Mancetter, Wild's Old Swelstone, Arnold's Brown George, Old Leicestershire, Young Leicestershire, Young Drayman, Sultan, etc.

Some forty-five years later another famous entire, known as Wisemann's "Honest Tom," was serving mares, and many of the best Shires of to-day can trace their pedigree in a direct line back to this famous sire.

\section{POINTS OF THE SHIRE.}

General Appearance.-A stout hodied, broad chested, short legged, heavy horse, with long quarters and strong loins. the hair of the mane 


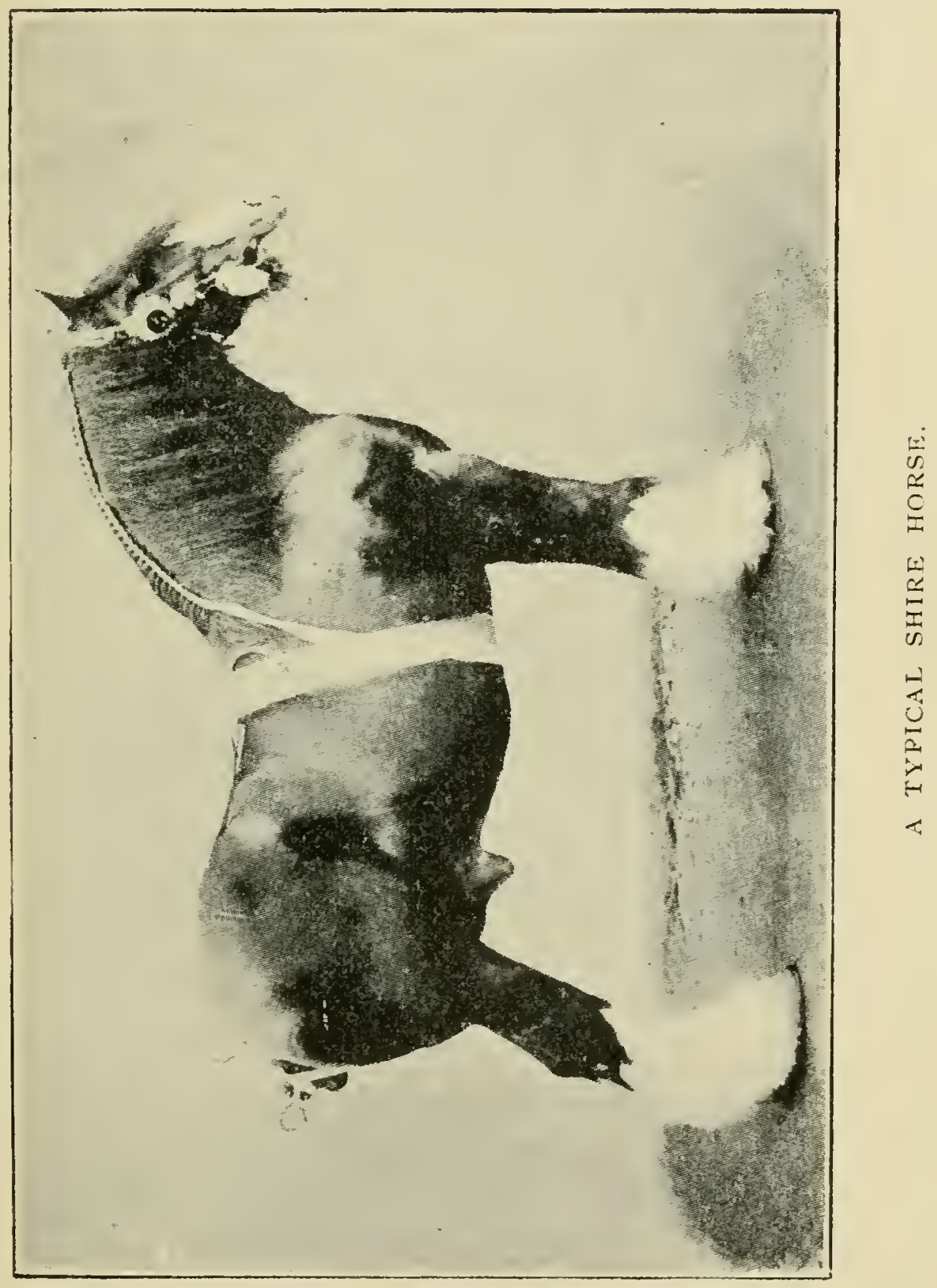


being fine, long and silky, with a corresponding condition of hair from the lower parts of the limbs. Coarse hair in these regions is indicative of inferior breeding.

The most characteristic feature of the typical Shire is his heavy compact body and short powerful limbs and quarters.

It is in weight of body that the Shire excels over his rival, the Clydesdale.

Head-Broad across the forehead (4), broad towards the point of nose and "set on " obliquely. Muzzle (I) should be fine and have a "tassel" of fine hair-a characteristic of the true Shire.

Eyes (5) full, but free from vicious expression.

Neck (6) short, well arched, passing below into deep and powerful shoulders (7). Withers (I5) thick and broad. Great width and depth of chest are a sine qua non in a Shire. 
Quarters long (22) and broad, Loins (I8) broad and muscular to a degree.

The Back (I6) must be short and broad; the girth (I 7 ) deep and full, with well sprung ribs (20).

Any tendency towards "weedyness" in the barrel is the worst fault a Shire can have.

The Hocks (24) must be broad in front, wide from front to back, and sharp in outline. Any swelling, fulness or disease, objectionable. Free hock action is a sine qua non.

Hips (25) wide and square.

Croup (26) slightly sloped.

Tail (27) This should be covered with long soft hair (no coarseness), and spring from the level of the croup with. the quarters.

Fore Arn (9) of moderate length, broad, thick and firm, ending at broad knees covered by thin skin. The knee (II) of the Shire should be almost 


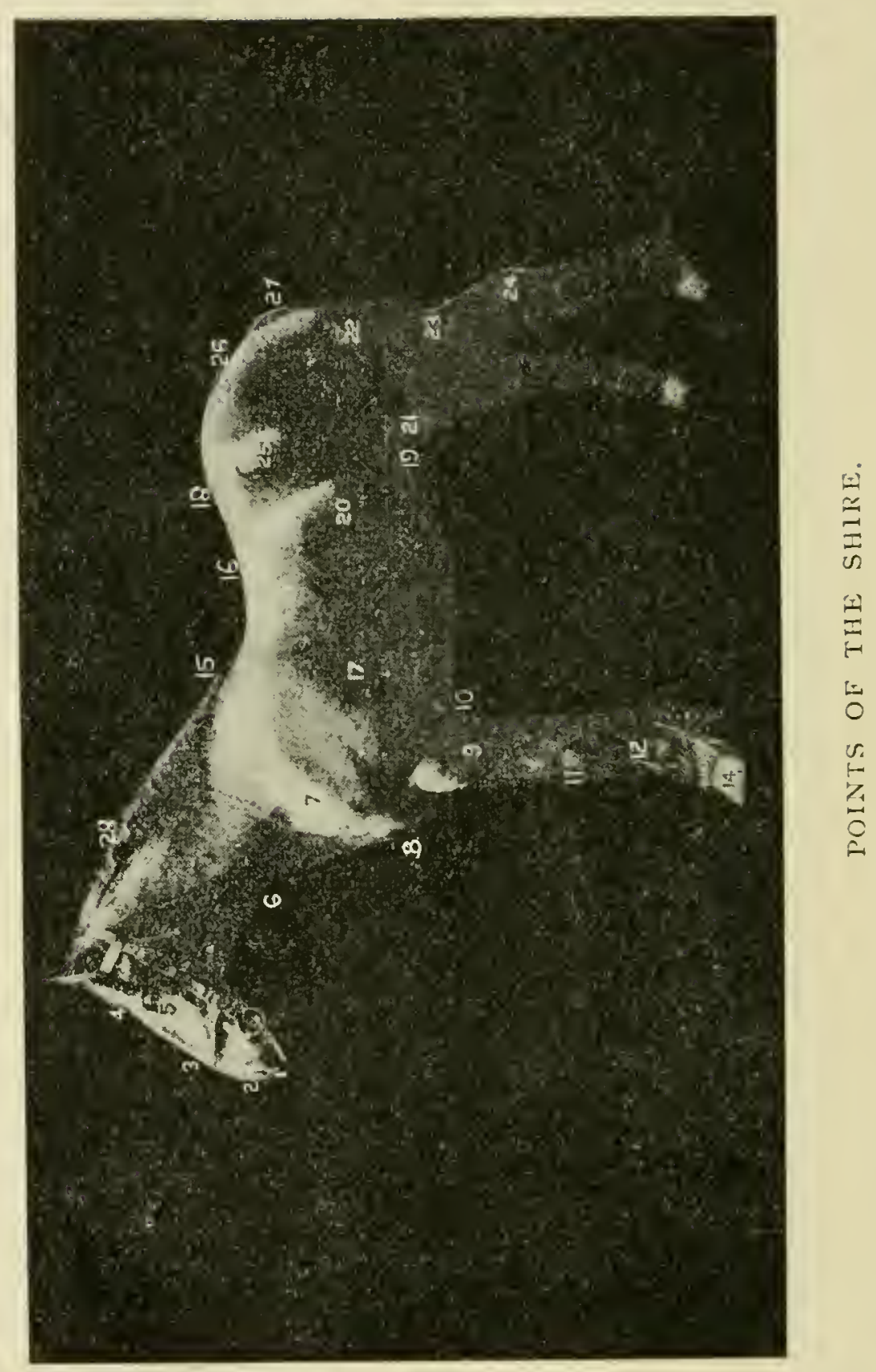


SOUND AND UNSOUND HORSES

square in outline, i.e., broad, flat, and clean.

Cannons (I2) short, broad and cylindrical, and when the hand is run down this region, nothing but skin, bone and tendons should be felt; in other words, the animal should be " cleanlegged," with a superabundance of soft silky hair, hiding, in part, the hoof. Pasterns (I3) strong, wide and clean. As to the feet (I4) these must be free from flatness, but large and full, well open at the heels, the sole being sound and concave, with a plump footpad (frog).

Pasterns broad, thick, neither too long nor too short, nor yet upright, or too oblique. An angle of moderate slope is necessary in a typical Shire.

Too much attention cannot be paid to the feet of horses when selecting, more especially so in the case of a heav! draught horse. 
In colour, Shires vary very much, and winners are of all colours: red roans, blue roans, iron greys, light greys, white, dark browns, light and dark bay, chestnut, etc., are all frequently met with. Many have white points.

The Shire is a quick mover at his walk, and when asked to trot, his action round and full.

The temperament of the breed is, generally, that of being kind and willing workers, always working up to the collar.

\section{CONDITIONS OF ENTRY INTO SHIRE HORSE SOCIETY'S STUD BOOK.}

\section{CONDITIONS OF ENTRY FOR STALLION.}

A Stallion foaled in I89o, or before, will be admitted if his sire and also his dam or dam's sire are registered.

A Stallion foaled after I89o will be 
admitted if his sire and dam are both registered, except when the dam has had produce previously registered, when the registration of the dam may be dispensed with.

Note.-If the dam of a Stallion foaled in I89o or before is not registered, her age, colour and breeder's name and address must be stated, and certificate $\mathrm{B}$ must be signed by the dam's breeder, unless the dam has had produce previously registered.

The Editing Committee are empowered to reject or to cancel the entry of any animal of which there is a doubt as to its being of the "Shire" or Old English cart horse breed.

\section{CONDITIONS OF ENTRY FOR MARE OR FILLY.}

A Mare foaled in 1885 , or before, will be admitted if her sire is registered, and also her dam or dam's sire. 
A Mare foaled after I885 will be admitted if her sire and dam are registered; or if she has three crosses of registered blood, viz., registered sire, registered sire of dam, and registered sire of grand-dam-but the third registered cross may be dispensed with in the case of animals out of Mares any of whose produce shall be proved to be previously registered.

Note.-If the dam is not registered or has no registered produce, and if the grand-dam is not registered, or has not already appeared in a registered pedigree, the age, colour, and breeder's name and address must be stated. Further, if the dam is not registered, a certificate will be required from her breeder, unless she has had produce previously registered. If the granddam is not registered, a certificate will be required from her breeder, unless she has already appeares in a registered 
pedigree. Failing a certificate the breeding must be anthenticated to the satisfaction of the Committee.

The Editing Committee are empowered to reject or to cancel the entry of any animal of which there is a doubt as to its being of the "Shire" or Old English cart horse breed.

\section{THE SUFFOLK.}

The Suffolk of to-day can be traced in a direct male line to one horse born in I760. As far back as 200 years since the Suffolk appears to have existed as a distinct breed, the colour then being as now, either chestnut, or this in combination with white.

In an unsigned copy of "Youatt on the Horse," the following paragraphs with reference to this breed of horse occur :-

"Horses of slow draught, and sometimes even for the carriage are produced 
from the 'Suffolk Punch,' so-called from his round 'punchy' make, and descended from the Norman stallion and Suffolk cart mare.

"The true Suffolk is now nearly extinct. It stood from I5 to I6 hands, and of a sorrel colour; was large headed, low shouldered, and thick on the top; deep and round chested; long backed, high in the croup; large and strong in the quarters; full in the flanks, round in the legs, and short in the pasterns. It was the very horse to throw his whole weight into the collar, with sufficient activity to do it effectually, and hardihood to stand a long day's work.......

"The Suffolk would tug at a dead pull until he dropped.

"The immense power of the Suffolk is accounted for by the low position of the shoulder, which enables him to throw so much weight into the collar." 
From the foregoing it will readily be gleaned in what esteem this variety of horse was held when the above was written.

Stands the Suffolk where it did.

Longevity and vitality are, amongst many others, two characteristics of the breed.

For breeding artillery horses no better class of animal can be found.

In height the Suffolk should be about I6-I hands; have long, low, muscular shoulders, great width over the hips, and broad, powerful, well rounded quarters.

A wide and deep chest, wide quarters, well sprung ribs-deep towards the flank-and a short stout neck, are essentials.

The back should be short and broad, and the legs short and muscular ; knees broad, and short from the knee to the fetlock. 
Typical Suffolks are very clean legged, and as a rule, have the best of feet.

A good Suffolk must be "wide" and "deep" in all his points, and well balanced withal.

Chestnut is the typical colour. Freedom from coarseness is necessary. In action the Suffolk is quick in all his paces; his temper - with rare exceptions - of the best, and he is constitutionally second to none.

As a heavy vanner, for the brewer, miller, and agriculturist, etc., he has no superior. The following are the conditions of entry for the registration of a horse by the Suffolk Horse Society.

\section{SUFFOLK HORSE SOCIETY. CONDITIONS OF ENTRY.}

All entries to be submitted for examination to the Council, who alone shall 
decide whether the animal is eligible for registration; but no entry shall be accepted which does not comply with the conditions adopted by the Society. These conditions are :

(A) No Stallion which is known to have a cross of any other breed in the direct male line within four generations, and no Mare within two generations, shall be admitted.

(B) No horse otherwise than of a chestnut colour shall beadmitted, but white or silver hairs well blended with chestnut shall not be held to be ground of objection, provided the quantity of such does not amount to a decided roan.

(c) No entry shall be rejected on account of white on the face or legs, nor be subject to limit as to height, weight or size. 
(D) No entries shall be admitted unless the sire of the dam be eligible for, or entered in, the Suffolk Stud Book; or that the dam be already entered in any of the volumes of the Suffolk Stud Book.

(E) When a Mare has once been registered, every subsequent generation must also be registered, to enable her descendants to be eligible.

(F) Animals bred outside Great Britain must be by a registered sire and from a registered dam.

(G) Entries must in all cases contain particulars as to markings (if any) or clearly state wholecoloured chestnut, chestnut alone not being sufficient. Should the above bye-law not be complied with, the entry will be liable to disqualification. 
SOUND AND UNSOUND HORSES

(H) The foregoing conditions shall apply to Stallions, Mares, Colts and Fillies.

All cases of suspected or doubtful pedigree of animals entered or submitted for entry, or alleged mis-representation, which shall be brought under the notice of the Society, shall be dealt with by the Council.

The Council shall have power to exclude from the benefits of the Society any person who knowingly makes a false entry.

All entries to be made on the printed forms supplied by the Society, and the Secretary shall be at liberty to return all forms not properly filled up, nor completed as to markings on face, etc., number in former volumes of sires, dams, etc.

Prefixes or affixes to the names of horses and mares can be registered, provided such be approved by the Council, 
such prefix or affix to be the sole right of the Member registering, or his representatives, during the period he is a Member of the Society. Except a prefix or affix be registered, no prescriptive title can be claimed.

Registration Fee, fI. Animals entered as foals: Stallions, Ios., Mares, $5^{\mathrm{s}}$; entered as yearlings: Stallions, 20s., Mares, Ios. ; entered as two year olds and upwards: Stallions, 4os., Mares, 20s. Transfers, 5s. Non-Members, double fees.

\section{THE CLYDESDALE.}

This is a hardy breed of horse, originally bred in the valley of the Clyde, and now most extensively reared - either pure or mixed-in almost every part of Scotland.

Amongst the farm horses in Scotland. we believe that we are not far from the truth when stating that fully three parts 
of these horses are about three-quarter Clydesdales.

As a rule they are big, powerful horses, rather leggy and deficient in body, yet of very vigorous constitution, and able to perform work that could not be done by more typically bred heavy horses.

The demand for Clydesdales is not as great in England as in the land of their nativity, yet greater than Scotland's demand for our beautiful Shire.

There is plenty of room for the best horses of both classes, and a ready market for such. The Clydesdales are particularly strong pullers, a very necessary quality considering the large amount of ploughed hilly land in Scotland. It is at times truly wonderful to see some of these horses toiling away before a plough over almost perpendicular braes, and many of these being, practically, only colts.

In colour the most typical specimens 
of Clydes are dappled brown, with a "ratch" (white streak) on the face, frequently white on the legs, and from I6.2 to I7 hands in height.

The chest should be broad, the neck strong and broad, ending in oblique shoulders. Fore arms long and broad, ending at broad, flat knees, below which the cannons and pasterns should be broad and thick, covered by thin skin.

A typical Clydesdale ought to be very "clean" legged, and from it there should be an abundance of long soft hair-free from coarseness.

Many horses, no matter what the breed, are very defective in the regions of the pasterns and feet. Some are too upright, have pasterns too short, others too long, or too oblique.

The happy medium is requisite in the Clyde, as in most other horses.

The foot must be proportionate and sound. Ribs wide and deep, and back 
somewhat short. Many Clydesdales are defective in these regions-a fact well known to admirers and breeders.

The hind quarters are specially powerful, and the legs long. Strong broad hocks are indispensable, but they must not be coarse to be typical.

Many farm horses have this latter fault. As in the lower parts of the fore limbs, there should be plenty of long silky hair.

Clydesdales are quick steppers, and have a long stride.

In point of colour, as already stated, dappled brown is the favourite one, then black. Most black Clydesdales have some white about them, more rarely without. Chestnuts, roans and greys are not looked upon as colours to appeal to connoisseurs of these animals, and are not encouraged by the society (Clydesdale Horse Society) watching the interests of the breed. 
SOUND AND UNSOUND HORSES

\section{VANNERS.}

Provided that the right stamp of horse be found, it matters not what breed it be, in fact, most Vanners are crossbreds, the results of mating a Clydesdale or Shire horse with a Hackney or crossbred mare.

Van horses are more or less " chance " productions in the majority of instances.

They are divisible into two classes:

(a) Light Vanners;

(b) Those used for heavy work.

As nearly all van horses have to do their work at the trot, they must not be too heavy in body.

For breeding Vanners, a most excellent cross would be that of a Suffolk entire with a stoutly built Hackney mare. Tolerably regular results might be hoped for, and a better standard of van horse produced. One meets with all sorts and conditions of van horses. but to accomplish this class of work 
successfully, good legs and feet, combined with a hardy constitution, are necessary.

Colour is unimportant, though when selecting a horse for these purposes, some clients have a preference in this respect, and will often forsakea superior animal to gratify their tastes.

From $I_{5}$ to $I 6 \frac{1}{2}$ hands are the usual heights for a van horse, and the best age to buy one at is 5 "off" or "rising" 6 yęars. For this class of work it is a mistake to buy one any younger. Well rounded ribs, strong shoulders and fore-arms, broad clean hocks and knees, and powerful loins and quarters are necessary qualifications for a good vanner. 


\section{CHAPTER V}

\section{WELSH PONIES.}

THis is an ancient breed of pony, but from time to time has suffered through want of suitable protection and attention.

In the early part of the I8th century there existed a very famous little racehorse called "Merlin," and when this horse became broken down for the turf he was sold to a gentleman, and turned loose to run with the droves on the Welsh hills.

The results of this experiment was an improvement in the breed, although this 
was not sustained, all the best being purchased.

The next step was the introduction of Norfolk Hackneys. The typical Welsh pony is from Io to $I 2 \frac{1}{2}$ hands in height. The best work towards the welfare of the breed has been done by the Church Stretton Hill Pony Improvement Society.

The Welsh Pony and Cob Society, founded in I902, bids fair to place the Welsh pony on a proper foundation, and this Society has made four divisions as follows :-

Class A.-Pure Welsh Pony not exceeding I2 hands and 2 ins.

Class B.-Ponies from I $2 \frac{1}{2}$ to $I 3 \frac{1}{2}$ hands, when a cob cross has been introduced direct from the Welsh Pony.

Class C.-Ponies from $13 \frac{1}{2}$ to $14 \frac{1}{2}$ hands having more cob blood in them. 
Class D.-Welsh Cobs from I $4 \frac{1}{2}$ to I5 $\frac{1}{2}$ hands, the largest of Welsh bred horses.

The following are descriptions of the points, etc., of Welsh Ponies, as furnished by the local Committees :-

\section{North Wales Division.}

Height not to exceed I2 hands 2 ins.

Colour :-Bay or brown preferred, grey or black allowable; but dun, chestnut, or broken colour considered objectionable.

Action:-Best described as that of the hunter, low "daisy-cutting" action to be avoided.

The pony should move quickly and actively, stepping out well from the shoulder, at the same time flexing the hocks and bringing the hind legs well under the body when going.

General Characteristics. - The pony should show good "pony" 
character and evidence of robust constitution, with the unmistakable appearance of hardiness peculiar to mountain ponies, at the same time have a lively appearance.

Head.-This should be small, well chiselled in its outline, and well set on ; forehead broad.

Nostrils large; eyes prominent, mild and intelligent.

Ears neatly set, small. Neck strong. proportionate, with moderate crest. Shoulders should be well laid back, and oblique, but not too fine at the withers. Back and loins strong.

Hind Quarters long, tail springing well from the top of the back, as in the Arabian.

Hocks well let down, fine, yet broad; curby, or low hocks, faults. Fore legs, well placed, strong fore arm. Short cannons. Good open feet, sound and hard. 


\section{South Wales Division.}

The South Wales Hill Pony seldom exceeds I3 hands. His attributes are sure-footedness and straight action.

Has low withers, short forehand, a "low" set on tail, but sickled (overbent) hocks, though fore legs and feet are good.

Constitution strong.

Of late years has been crossed with the Cardiganshire Cob to some extent. Also half-bred two year old Shire colts have been allowed access to the hills during the summer in some places, much to the detriment of the breed. As to colour, bays and browns prevail.

\section{SHETLAND PONIES.}

There is little doubt as to the "Sheltie" being a distinct breed several hundreds of years since. Brand visited the islands of Orkney, Shetland, etc., 


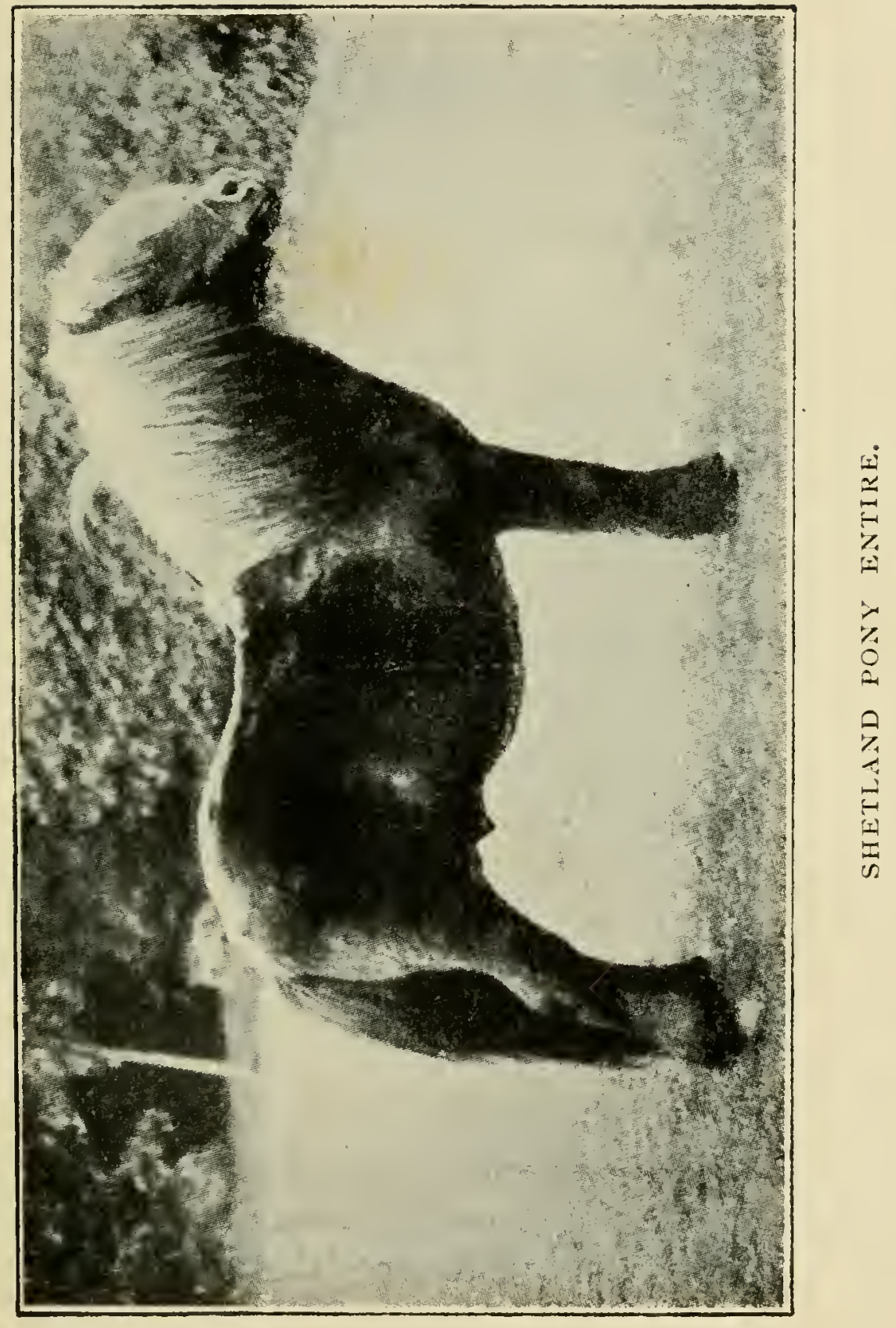

G 
and a published account of his risit is as follows :-

"The Shetland Ponics are of less size than the Orkney horses, for some will be but 9, others Io nives or hand breadths high, and they will be thought big horses there if II, and although so small, yet they are full of vigour and life, and some not so high as others often prove to be the strongest..... . Summer or winter, they never come into a house, but run up the mountains in some places in flocks; and if any time in winter the storm be so great that they are straitened for food, they will come down from the hills when the ebb is on the sea, and eat the seaware......which winter storms and scarcity of fodder puts them out of ease, and bringeth them so very low that they recover not their strength till St. John's Mass Day, the 24th of June, when they are at their best. "They will live to a considerable age, 
SOUND AND UNSOUND HORSES

as 26,28 or 30 years, and they will be good riding horses in 24, especially they'll be the more vigorous and live longer if they be four years old before they be put to work.

"Those of a black colour are judged to be the most durable, and the pyed often prove not so good; they have been more numerous than they now are."

From the foregoing account we learn that our present "Shetlander" pony has not lost the qualities attributed to him by Brand.

$\mathrm{He}$ is as hardy and strong as ever ; as sure-footed and as small as he used to be.

The average height for a Shetland is Io hands, and the Shetland Stud Book Society does not register ponies above Io hands 2 ins. Ponies 9 hands. are not uncommon, but anything below this is exceptional, certainly not the rule. 
Most of the prize winners are 9 and Io hands or thereabouts, and in colour brown, black-brown, bay, more rarely chestnut. Many have white markings, and some are piebald.

The breed is as hardy as they "make 'em," and will do hard and fast work on poor food. In point of size, for endurance, weight-carrying and cleverness all round, they have no superior, if an equal.

One of the best small ponies the writer ever drove was a dark brown Shetland, to name, "Sammy." He could carry his "tub" with three people in it, at eight or nine miles an hour, and keep it up.

In the autumn and winter the coats of these ponies get very long unless the best of grooming, clipping, etc., is carried out. To work in this condition is considerably against them.

It is quite exceptional to find a bad 
tempered Shetland, although they are not all suitable for children, some being rather too strong in the neck.

At the same time, it goes without fear of contradiction, that a well broken Shetland forms an ideal pony for a child, either for saddle or harness purposes.

Shetlands are used in coal pits, working in low galleries where the pit is thin seamed.

The long flowing mane and tail, the long forelock, the short back, short legs and broad short head, are characteristic features of the Shetland.

The fore arms should be strong and broad, cannons short and clean, pasterns oblique, and hoof at angle of about 45 degrees.

A common fault is upright boxy feet. Action should be good-moderately high, fore and aft; quarters strong; back broad. 


\section{EXMOOR AND DARTMOOR PONIES.}

\section{THE EXMOOR:}

This is an ancient breed of pony, and in its natural state has degenerated through picking out the best animals of the droves, without exercising care in the selection of suitable sires.

Sir Thomas Acland and Mr. Knight (deceased I850), took a keen interest in the welfare of these ponies, and did much towards their improvement.

Arab blood has frequently been introduced, sometimes with marked benefit.

The Exmoor should not exceed I3 hands, the average being I2 hands.

A "mealy" nose is a characteristic.

In colour, dark bay or brown, with black points. Legs, short, and back strong.

To buy Exmoors, one of the best 
SOUND AND UNSOUND HORSES

places to go to is Bampton Fair, held in October.

\section{DARTMOOR PONIES.}

These ponies are usually brown, black or bay, and should not exceed I3 hands in height.

The neck should be strong and of moderate length.

When trained, they make good boys' hunters, are good stayers, and, like the Exmoors, very sure-footed.

\section{RUM = PONIES, OR THE GALLOW AY.}

The pure Galloway was said to be nearly I4 hands, and of a bright bay or brown, with black points, and had a small head, clean legs, stout body and was very shapely. These Galloways are reckoned to have had marvellous powers of endurance, and were sure-footed. In 
I840 the late Marquis of Salisbury brought to light a breed of Black Galloways from the Island of Rum, then in a wild state on the island. Characteristic features are said to be found in the colour of their eyes, which are hazel, the long croup, and big head.

These ponies have good quarters, and are first class stayers, though they may be but poorly fed.

\section{NEW FOREST PONIES.}

From records, it is evident that this variety of pony was in existence at least Iooo years since. The present qualities of the "Forester" are chiefly due to a horse called "Marske," the sire of the immortal "Eclipse" (foaled I764), so that these ponies have a great deal of thoroughbred blood in them.

This entire was barely I4.2.

Subsequent to this improvement, the best ponies were sold and no attempt 


\section{SOUND AND UNSOUND HORSES}

was made to keep up the standard until the Prince Consort introduced a grey Arab entire into the district, and this gave new life to a fast degenerating race of ponies.

In the present day, Lord Arthur Cecil turns out a number of black stallions, imported from the Island of Rum (Scotland) first about I840, by the late Marquis of Salisbury. The cross has evidently been of marked benefit to the New Forester.

General Appearance.-Height I2 to I3 $\frac{1}{2}$ hands. With better keep these ponies will increase three or four inches in height. The so-called flea-bitten greys are very numerous, but these ponies are found in a variety of colours.

They are considered to be good tempered when broken, but troublesome to overcome.

Have fair shaped shoulders, but croup is generally of bad shape.

$$
\text { I05 }
$$




\section{CONNEMARA PONIES.}

Connemara, in the County of Galway, apparently had, like Orkney and Shetland, a variety of horses peculiar to its locality.

The origin and excellency of these ponies seems to be due to the introduction of Eastern sires-Arab or Barb, but within the last twenty or thirty years the breed has been degenerating, though more recently attempts have been made to resuscitate it.

These ponies are from I 2 to I4 hands in height, have clean wiry limbs, and long lean (Eastern) heads.

In colour, yellow-dun, bay or grey.

Croup to be as high as the withers.

Neck strong and of medium length ; shoulders straight; withers medium height, long body, deep (63 to 70 ins.) : legs short and strong. Cannons $6 \frac{1}{2}$ to 7 inches in length. Loins must be strong and quarters well sloped. 
SOUND AND UNSOUND HORSES

The Connemara Pony Committee gives the distance between the eyes $7 \frac{1}{2}$ to 8 inches, and the length of the leg from elbow to ground from 3 I to 33 inches.

These ponies are specially suitable to train for polo work.

\section{POLO PONIES.}

Given the right stamp of pony, it does not matter what be his breed or his nationality.

Before it can lay claim to be called a Polo Pony, the animal must be made to the game, when it may have increased in value from that of a few pounds up to three figures. Speed, strength and staying power are essential qualifications in the raw material. The height should be I4.2.

In India, the Polo Pony, playing under the Association's code of rules, must not exceed I3.3. 
As to conformation, the back should be long, and loins short.

The shoulders, long and muscular to a degree, and neck carried vertically. Withers low; ears small and pointed; fore arms long, broad and muscular; broad, "clean" knee and hock joints ; pasterns of moderate length, and of good slope. In general build a polo pony wants to be a small "stoutly" built (if such an expression can be used) thoroughbred, and the best means of producing these ponies will be by means of a small thoroughbred sire. 


\section{CHAPTER VI}

THE AGE OF THE HORSE

Although irregularities as to time do occur in connection with the appearance of the incisor or nipping teeth, these exceptions are not sufficiently numerous to disturb the "accepted" and universal system of judging a horse's age by his teeth. At, or shortly after the time when the foal comes into the world, he has two sucking or temporary incisor teeth in the centre of the upper jaw, and a corresponding pair in the lower. These are the centrals.

In an interval of from six to eight 


\section{SOUND AND UNSOUND HORSES}

weeks, another pair appear in both jaws, known as the " middles," or laterals. Between this and six months there is a

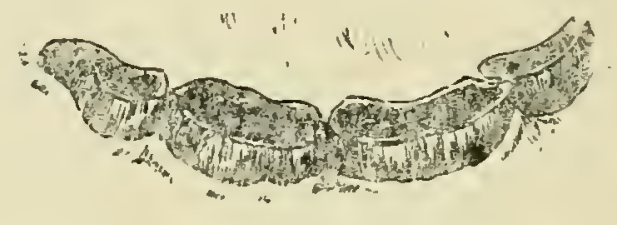

INCISORS AT TWO MONTHS.

period of "dormancy" as it were, no more incisor teeth making their appearance. Very shortly after the period last named, the "corner" incisors will be seen, and by the time the colt is one year old, the "corners" are on a level with the centrals and laterals, so that

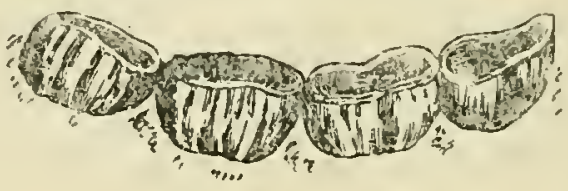

INCISORS AT SIX MONTHS.

the animal has now a complete set of sucking or incisor sucking teeth, all of which remain in the mouth until the colt has turned two years. It is very 
necessary to be able to tell a yearling from a two year old, about which there should be no difficulty, even without settling up the point by reference to the

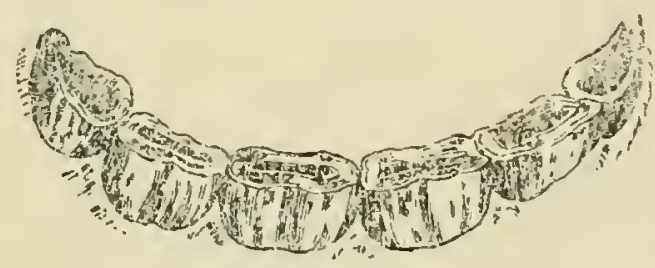

INCISORS OF A YEARLING.

molars. Look at the tables of the corner incisors, which are not formed at one year, but as a rule, well in wear at twenty months and twenty-four months.

All the wearing surfaces of these teeth are reduced much more so than in the yearling, and the mouth broader. The presence of the "fifth" molar is, of course, positive evidence that the animal is not a yearling, this tooth not making its appearance until about one and a half years. In calculating the age reckon from January Ist, though 
many foals are born early in February, and the majority in March or April, thus making a slight difference in the appearance and development of the permanent incisors.

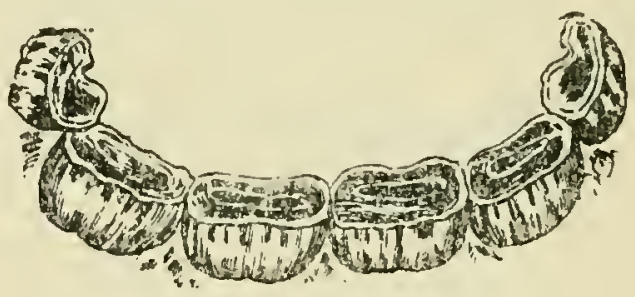

INCISORS AT TWO YEARS.

The application of the terms "rising" and "off," means that the animal is within, say, three months, or thereabouts, of its reputed age.

Many horse dealers make a practice of selling a horse that is barely three years old as one rising four, with a corresponding misrepresentation of a four for a five years, and the latter for a horse at six.

In order to guard against such deceptions, particular attention must be paid 
to the form of and wear upon the tables, in other words, to the shape of the mark or infundibulum, to the ring of enamel surrounding this mark, and to the outer enamel ring, or the boundary of the tooth.

The term "anterior" is applied to that portion of the table lying between the free edge of the tooth and the front edge of the "inner" enamel ring; "posterior," to the space lying behind it.

Another important matter is that of being able to readily distinguish "temporary" from permanent incisors. The former are smaller, narrower where they enter the gum, and are without any well defined groove running up the face of the tooth, so pronounced in the permanent broad incisors. The replacement of the temporary by the permanent teeth begins at the "centrals," followed by the middles and corners. In most in- 
stances, when noting the animal's age, it is usual to inspect the incisors in the lower jaw only.

\section{SHEDDING THE INCISORS.}

Two Years Off.-If the gums are examined they will be seen to be congested, and the new central permanent incisors either through, or breaking through the gum.

Two Years and a Half. - The central pair of permanents are just about half way up, and have each a cavity running across the nipping surfaces. The difference between them and the worn temporary ones is very striking.

Rising Three Years.-Sometimes it becomes an urgent matter to decide whether a colt is "Rising three years," or "Three years off."

Look very critically at the middle 
teeth for evidence of congestion of the gums.

If this is present, it is fairly reliable evidence that the colt has turned three years. This opinion is strengthened if the tables of the centrals are fully developed, whereas in a "Rising three"

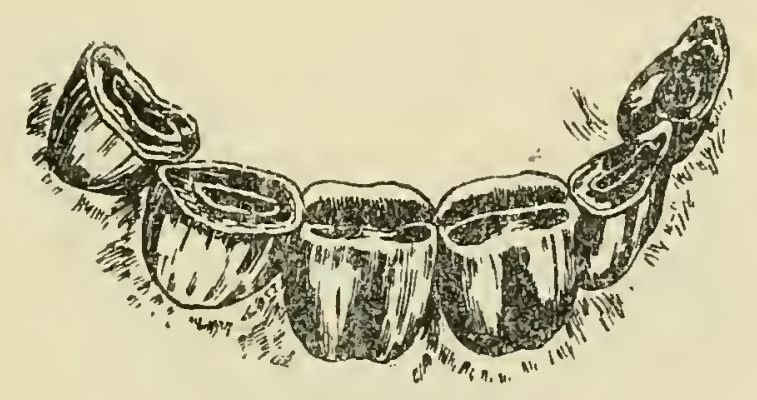

INCISORS AT THREE YEARS.

it is unusual to have the tables properily formed, the mark running right through each of the new teeth, with, probably, wear on the front edge of the tooth only.

Three Years.-The drawing represents the condition of the lower incisors in a horse just three years of age.

Three Years Off. - We have already 
referred to this under the heading of "Rising Three."

\section{Three Years and Six Months.-} The middle pair of incisors is now about half way up, and they bear the same relaticnship_so far as appearances go -to the temporary "comers," when the mouth is closed.

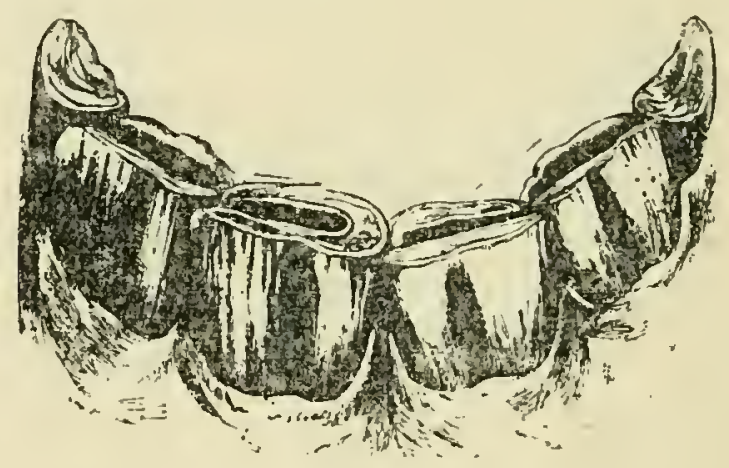

INCISORS AT FOUR YEARS.

Rising Four.-A veterinary surgeon is frequently called upon to decide as to whether a particular animal is rising to his fourth birthday, or whether he has passed it; in other words, four " off."

The best evidence will be gleaned by 
looking for signs of congestion of the gum or inception of the "corners."

If this is present it is fairly good positive evidence that the colt is "four years off," an opinion materially strengthened if the tables of the "middles" are well formed. In a rising four years old the mark in the middle teeth is in the same condition as that described under a "rising three."

Four Years and Six Months.-

The "corner" permanents are now just about half way up, and they are easily distinguishable from the temporary incisors which they displaced at or about four years and a quarter. Their nipping surfaces have not yet come into play, so that there is no wear here-so far.

Kising Five. - The corner incisors at this age have just reached the level of the other permanents, but their cutting 
surfaces are not in wear as yet. The mark is large, and the teeth shell-like.

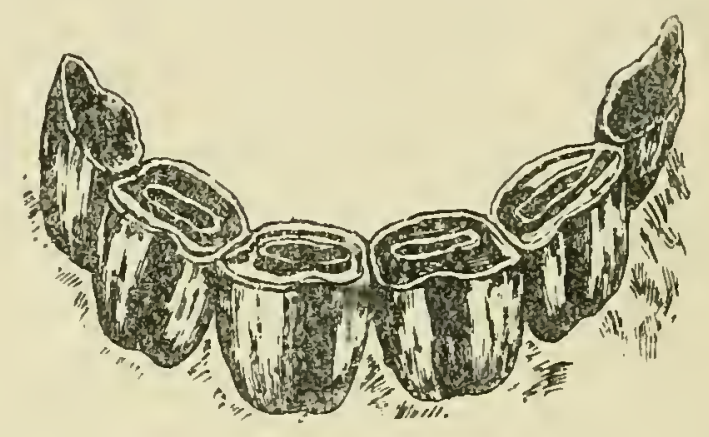

INCISORS AT IIVE YEARS.

Five Years Ofi. - The front edges of the "corners" show wear, but the tables are not formed.

Six Years. - It is very important to be able to determine the animal's age at this period of life.

With some dealers it is a general rule to sell nearly all their horses as six or seven years old, as so many people prefer to purchase horses at this age.

The best evidence is that obtained by a careful inspection of the comer incisors. In a six year old, these teeth have less 
wear on the hinder edge than in front, and the central mark is still deep, whereas in the central and middles it is

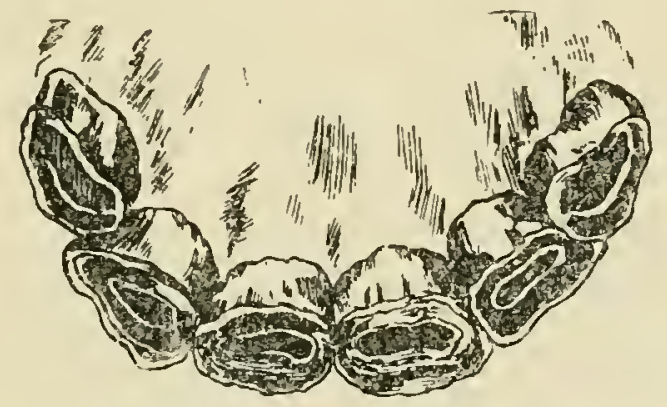

INCISORS AT SIX YEARS.

comparatively shallow, and the tables are not of the triangular form assumed at seven.

It is not at all uncommon to find the "corner" teeth having the posterior border below the level of the anterior, and remaining in this condition, so that it is quite easy to give an opinion that the animal is six years. Under these circumstances, the shapes of the "marks" and tables in the centrals and middles should be noted. 
In addition to this, there will be a great deal of wear on the front edge if over this age.

It is frequently a very difficult matter to decide. Reference to the illustration may be of some assistance. Seven Years. - The author has known horses up to twenty years offered for sale as seven years old. Of course, no veterinary surgeon would err in this way. The question most likely to arise is whether the horse is seren or eight.

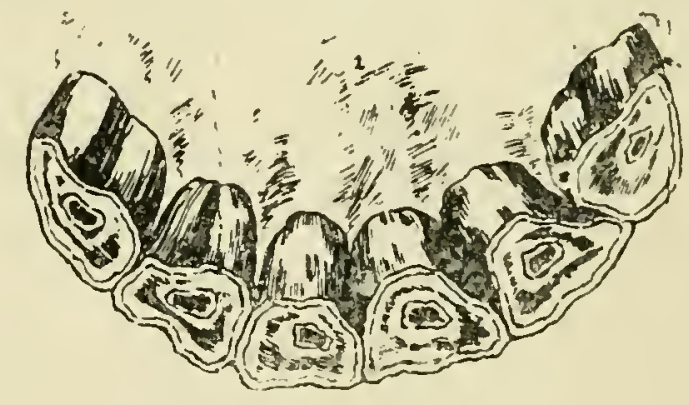

INCISORS AT SEVEN IFARS.

These differences are fairly well marked if the form and rear of the marks and tables be appreciated. In the comers 
the mark is still elongated at seven, whereas at eight this is circular, or it may be, obliterated.

Eight Years. - In the centrals, middles and corners the mark is either very attenuated, or lost. If it exists,

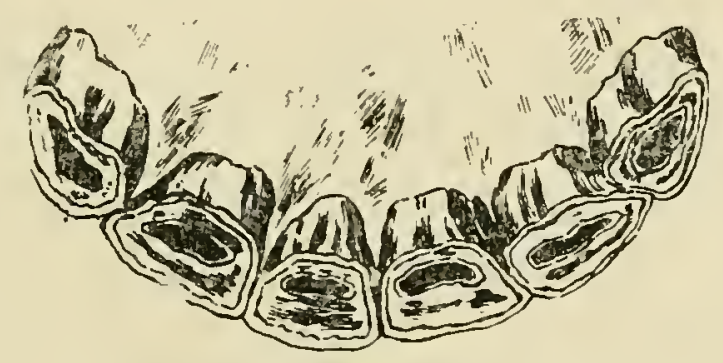

INCISORS AT EIGHT YEARS.

it is practically reduced to an irregular circle.

Nine and Ten Years. - Teeth becoming longer, and increasing in obliquity. Animal now spoken of as aged.

After ten years, the upper corner incisors begin to show the groove (clos? to the gum) described by Galvayne, but as many horses have the whole of 
their incisors grooved, it is only a speculative means of judging an aged or old horse.

\section{'TUSKS (WHEN PRESENT) AS EVIDENCE OF AGE.}

It is not advisable to place much reliance upon the tusks as indicators of age, though reference to them (if present) may be of some assistance taken along with other evidence. In Shetland mares the tusks are commonly present, and as well developed as in the horse.

It is usually about the fourth year that they " show up," becoming blunted at seven years, more so at eight. At six years they are sharp, and their inner surfaces hollow.

\section{MOLARS.}

It is rather singular that so few veterinary surgeons refer to these teeth. 
At certain ages they form a most reliable guide.

The fourth, fifth, and. sixth molars appear as permanent teeth, whilst the first, second and third are replaceable ones.

These teeth appear in the following order :-

Nine Months..- The fourth permanent molar breaks through the gum, and at

One Year it rises to the level of the three temporary ones in front of it.

One Year and Six Months. - The fifth permanent molar is through, and at

Two Years it is level with the fourth permanent molar.

Two Years and Six Months.-The first and second temporary molars are shed, if not, by the time the colt reaches two years and three-quarters (rising three).

Three Years.-First and second permanent molars fully up.

Four Years.-Third temporary molar 
SOUND AND UNSOUND HORSES

replaced, and the sixth permanent molar well up.

\section{SUMMARY.}

I. - That a yearling has a complete set of temporary incisors, and the fourth permanent molar on a level with the three temporary ones in front of it.

2.- That a two year old has a fifth permanent molar as yet not much in wear.

3.-That two fully (lower jaw) developed permanent incisors are positive evidence of a three year old.

4. -That at three "off" there will be signs of shedding of the middle temporary incisors, and at three and a half the permanent incisors will have replaced them.

5.-About three years the first and second permanent molars are well up.

6.-That a "rising four year old" is readily told by the fact that the permanent molars are "fully up," but the tables not properly formed. 
SOUND AND UNSOUND HORSES

7.- The characteristic features of a five years are well seen in the comer incisors, the wear being confined chiefly to the front edges. At this age all the teeth are on a level and the mouth has a very neat, full gum, semi-circular appearance.

8. - That the corner incisors may be as " shell teeth," thus misleading one, unless reference be made to wear upon their front edges, and the changes in the middles and centrals.

9.- That a seven years old has the "mark" in its " corners" slightly elongated, and at eight years round or lost.

And lastly, to bear in mind that when looking at the teeth re age, there is no cleverness in merely separating the lips and taking a casual glance at the faces and tables of the teeth.

Look at the tables of each tooth as to ts shape, and the shape of the mark, ts size in all the teeth, taking plenty 
SOUND AND UNSOUND HORSES

of time to appreciate the evidence thus afforded before pronouncing the age. Justice has to be done not only to the buyer but also to the seller. 


\section{CHAPTER VII}

DISEASES AND THEIR RELA. TIONSHIP TO UNSOUNDNESS

For the sake of convenience, the author considers it advisable to briefly allude to those diseased conditions recognised by the majority of veterinary practitioners as constituting unsoundness in a legal sense, and which occur in our daily examinations for soundness, dealing with these in what may be tabulated as the Regional System.

Unquestionably, many diseases will present themselves either to the mind or eye, of the student, to which herein no reference has been made. 
Were it possible to enumerate the multifarious ills affecting the Equidre in a small. work of this description, the advantages would hardly warrant their insertion. When it comes to a question of fact, a horse having disease upon it in any form is "unsound"; therefore, all diseases constitute unsoundness, and it is for the veterinarian, in virtue of his training, to discriminate and advise as to those abnormal conditions that are " temporary," " permanent," or likely to interfere with the present or future utility of the animal. Keen observation, tact, and sound judgment, are essentials as a means to this end.

Before alluding to the principal pathological states, it must be distinctly understood that no attempt has been made to enter the domain of Pathology, reference, as far as practicable, being confined to remarks in relationship to soundness, or otherwise. 


\section{I-NASAL REGION.}

Catarrh. - No matter whether acute or chronic, the examination should be deferred, or the certificate withheld pending resumption of the normal state.

Abnormal Growths.-Pedunculated or sessile, may occur in any part of the nasal passage, and have sometimes been overlooked. Are capable of producing abnormal breathing sounds (roaring or whistling), and might provoke litigation if overlooked: hence advisable to examine as high up the nasal cavity as possible.

\section{Stricture of Lachrymal Duct.--} Tears flow over eyelid.

Epistaxis.-Sometimes intermittent, consequently sure to be overlooked.

Deformity of Nasal Bone.-This may be congenital or acquired. The extent of the deformity, and whether 
SOUND AND UNSOUND HORSES

the animal suffers any inconvenience must be the guide.

Injuries to the Alar Cartilages.Defective respiration may be produced, the result of stenosis.

\section{2.-ORAL REGION.}

Irregularity of the Incisors.In the congenital defects, the so-called "parrot mouth," in which the upper incisors project beyond and lap over the lower ones-and in "reversad parrot mouth," - the converse, it is advisable when offered for examination, to point out the disadvantages to the intending buyer.

\section{Deficiency in number of Incisors.-} In rare instances-one of which we recently saw-the normal number may be deficient, reduced to four in the lower jaw, with a corresponding number in the upper. If so, it is unimportant, though 
interesting. The same remark applies to the acquired loss of an incisor.

Loss of, or Caries of Mo!ars.Always inspect the molars. Reject if either of these conditions be present. There may be some external evidence.

Paralysis of the Tongue.-This is not uncommon, but such animais are not usually submitted for examination as to soundness.

\section{Mechanical Injuries of Tongue.-} Unless severe, unimportant.

Actinomycosis of Tongue.-Always make a point of examining this organ. It is needless to add, if diseased, reject.

\section{3.-FACIAL REGION.}

As a rule, nothing is likely to present itself here in connection with examination re soundness. Facial paralysis is not common, and no one would think of submitting a horse with it for sale. 
The frontal and maxillary sinuses should be " percussed."

\section{4.-SUB=MAXILLARY REGION.}

Sub = Maxillary Glands.-- Very frequently enlarged, either through acute specific (strangles and glanders) disease, or as a chronic induration apart from either of these, or chronic glanders.

When forming an opinion as to the probable harmless nature of any growth in this region, special care must be exercised. It would be a pity to reject a good horse for what may be a comparatively harmless tumour. The history, if reliable, will be of service.

Fistula of the Duct.-Reject.

Bony Tumours.-Reject for all such growths.

\section{5.-PAROTID REGION.}

Fistula of the Duct.-Not uncommon. Reject. 
SOUND AND UNSOUND HORSES

Enlargement of Parotid.-This may be either acute or chronic.

\section{6.- OCULAR REGION.}

Entropion Ectropion.-Both uncommon.

Congunctivitis.-Usually acute; if so, defer examination. In its "chronic" form reject, as it predisposes to opacity of the cornea in the event of an acute catarrhal affection supervening.

Leucoma.-Reject. The same remark applies to nebulie.

\section{GLAUCOMA.}

Amaurosis.-May be "temporary" or permanent. The "pupil" is widely dilated, and the eye apparently healthy. If suspected, cover up eye that is sound and make horse move forward.

Keratitis.-In the foregoing three diseases, there is no alternative but to reject the animal. 
Cataract. -Examine both eyes very critically for the presence of this ocular defect. Some cataracts are very small, appearing, in the illuminated eye, as a stellate, greenish-grey opacity.

When using the catoptric test, bear in mind that there should be three images of the flame, viz., two erect, moving in the same direction as that of the candle, and one, inverted. moving in an opposite direction.

In cataract, the last named is either absent, or else indistinct. Ophthalmoscopic examination should be employed in doubtful cases.

\section{Adhesion of the Iris to the Lens.} -The pupil contracts irregularly if partially adherent. Frequently result of iritis.

Displacement of Corpora= Nigra. - Has been known to cause shying. 


\section{OCCIPITAL REGION.}

Examine for poll-evil, past or present.

\section{8.-CERVICAL REGION.}

Cutaneous Diseases (parasitic and non-parasitic). If present, defer examination, or withhold certificate until cured.

Enlargement on the side of Cervical Vertebra. - If present, reject.

Deformity of the Trachea.-Must be guided by own judgment. The writer has seen chronic forms of injury to the trachea that did not cause the animals the slightest inconvenience.

Disease of the Larynx-Roaring. No matter whatsoever be the cause of this abnormal sound, or as a modification of it, whistling, it constitutes unsoundness. In accordance with its causation it can be either "temporary" 
or " permanent," curable or incurable. In most instances it appears as a permanent and incurable state. On this account it behoves the veterinary surgeon to watch against passing a "roarer" or whistler for a client; yet any examiner might do so, without any blame being attachable to him. Degenerative changes of larynx muscles are, doubtless, the most frequent causes of roaring, or whistling, but abnormal growths and swellings in the region of the larynx and certain specific agents, are also known to be causes.

Intermittent roaring has been found to arise through the alteration in the position of a pedunculated growth. In this way one might easily pass a horse as sound in his wind, whereas almost immediately afterwards he might be making-and so might the buyer-a noise.

It is well-for veterinary surgeons at 
least, that there are such causes as those alluded to, because it may become expedient, should litigation ensue, to make use of this knowledge.

Unquestionably one of the best methods for testing a light horse's wind, is to strap up the near fore leg, and circle him on the longeing-with whip behind-rein at a trot for five or ten minutes.

Diseases of the Esophagus: Dilatation-Stenosis.-Presence very unlikely.

Jugular Vein.-Examine it for scar of venesection.

\section{DORSAL REGION.}

The withers require scrutiny for evidence of present or antecedent disease.

All practitioners know that many injuries, though "apparently" cured, have a tendency to recur. This state- 
ment also holds good for the occipital region.

Saddle Galls.-Past or present. Sometimes sore back is very troublesome, and if a purchaser finds that he has got a horse that readily "chafes," he is not, as a rule, very pleased about it.

Although apparently a simple enough matter, good judgment must be exercised if the client has to be pleased.

If the animal shows evidence of having been much troubled with a sore back, the writer would advise its rejection, although this opinion may not be a general one.

\section{IO.-LUMBAR REGION.}

Anchylosis. - This is not uncommon, especially amongst old horses. The best way for detecting it is by turning and backing (bending) the animal. 


\section{II. - SACRAL AND ILIAC REGIONS.}

As a rule there is not much to look for in the region of the croup. Bruises are not uncommon.

Fracture of External Angle of lium.-This is a fairly frequent accident, the point of the hip being knocked off. False union is a common result. To detect it compare the angles.

\section{I2.-CAUDAL REGION.}

Seldom anything of significance here unless it be some skin disease, or an evidence of " shivering." Raise the tail to inspect the anal aperture for presence of abnormal growth-polypus ani.

\section{I3.-SCAPULAR REGION.}

Paralysis of Supra = Scapular Nerve (Shoulder slip). — Not uncom- 
monly met with. Compare shoulders. If present, reject.

Sore Shoulders. - Pay particular attention to the conformation of the shoulders. Judge whether due to a badly fitting collar.

Veterinary surgeons are sometimes consulted as to whether they would advise the purchase of a horse affected in this manner. If shoulders are well formed and cause ascertained, advisenot unless-purchase.

\section{I4.-BRACHIAL REGION.}

\section{Sprain of Flexor Brachii.}

Capped Elbow.-No matter whether growth be small or large, stationary or progressive, reject, and this because the ultimate issue may bring discredit on the examiner. 


\section{I5.-ANTI =BRACHIAL REGION.}

Seldom anything particular presents itself for decision in relation to soundness in this region, unless it be a sprain, etc.

\section{I6.-CARPAL REGION.}

Critical inspection of the knee is always advisable, as bruises and blemishes are so very common here.

Bring the limb forwards and examine it in a strong light, and if needful with a lens. Manipulate the skin with the fingers. The presence of a cicatrix, or an irregular growth of hair, is indicative of the skin having been broken. White, or different coloured hair, may be the result of superficial abrasion.

The intending buyer must be notified as to the existence of such, no matter however insignificant. 
SOUND AND UNSOUND HORSES

Anchylosis.-Flex the knees. If any stiffness, reject. If an. acute swelling is the cause, defer examination.

Psoriasis, being a troublesome complaint, offers reasonable grounds for rejection. Confer with client.

\section{Bursal and Tendon Sheath Swell=} ings.-These swellings are frequently met with in examination; they are unsightly, yet may not be detrimental, but their presence predisposes the animal to an acute inflammation in this region should an exciting cause come into play, so that it is speculative as to whether such a non-inflammatory swelling may or may not interfere with the future usefulness of the animal, hence better to regard as unsound.

\section{I7. -METACARPAL REGION.}

It is in this region, and below it, that the examiner's skill and judgment is so 
frequently called into requisition, More differences of opinion arise here and beneath it, than over any otherhock excepted-parts of the equine anatomy, and the author makes no attempt to disturb the opinions of practitioners who are entitled to respect.

Opposition of professional opinion, though prejudicial at times-is useful as a means to an end, be that ending satisfactory or otherwise.

Speedy Cutting.-This is rightly regarded as constituting unsoundness, and few practitioners noting its presence-though frequently overlookedwould be disposed to pass the animal as sound. Scarring is usually found just below the carpus, on its inner side. High action and "turned in " toes are predisposing causes.

Splint.-Probably it is better to reserve the term "splint" for deposits of bony material confined to the back 
and postero-lateral aspect of the metacarpus, as distinguishable from abnormal deposits on the front and antero-lateral surfaces of this region, designated exostoses. Strictly speaking, this is incorrect, the two pathological states being precisely identical.

An extensive personal acquaintance with practitioners leads the writer to take this view.

It is a fairly widespread custom amongst veterinary surgeons to pass horses as sound-frequently without any prefixes in the wording of their certificates-having splint, provided that its situation is what they regard as harmless.

The argument in favour of the adoption of this plan is, that one would hardlyever find a sound horse, and when found he migint be useless. Unquestionably this is a hard fact, and one seemingly difficult to controvert. 
That a horse may have a slight or a large splint in a good position, and never go lame, is true, or the splint may undergo absorption, and so end the matter.

In the experience of the author it is equally true that a splint, placed in the very best position that it can occupy, has, to the regret of the buyer, produced most intractable lameness.

The so-called "knee splints" areand rightly so-looked upon with suspicion, and when detected, are sufficient cause for rejection. The author takes this view of all splints and exostoses upon any part of the metacarpus.

It is far too speculative to say whether such and such a horse will continue to go sound through the existence of these "apparently" insignificant osseous deposits.

Being abnormal, and viewed in a 
legal sense, their presence constitutes unsoundness.

Some practitioners-probably the more numerous - noting the presence of splints, certify as to "practical " soundness, a term that requires no explanation, but one, we hold, that is of very little value so far as the practitioner's reputation is concerned.

In the writer's opinion the more satisfactory plan is, if splints be present, to indicate their existence on the certificate, or by word of mouth, and add, " in all other respects (if this is the only fault) the animal is sound." Worded in this manner, the examiner protects himseli, probably without making the client fight shy of an animal that may be exactly what he requires, and possibly will have trouble in finding another as suitable.

In a heavy horse, it is right that less regard be paid to splints. 
SOUND AND UNSOUND HORSES

Sprain of the Flexors.

Sprain of the Suspensory Ligament.

Break= down.

Congenital and Acquired (other

than the above) Defects and Injuries.

\section{I8.-PHALANGEAL REGION.}

Bruising and Enlargement of Fetlock.-Slight puffiness, though usually indicative of wear, is unimportant. but if swollen or much bruised, reject. Flex the joint.

Ringisone.-No matter whether " high " or "low," "true " or " false," "back" or "front," reject. There can be no two opinions as to ringbone constituting unsoundness. The chief trouble that arises in connection with it is "whether a ringbone does or does not exist upon a certain animal.'

We are not aware that there is any 
royal way to solve this frequently "knotty" problem.

Every professional man, as an expert, is entitled to his opinion, be it correct or incorrect.

If a ringbone is well marked, it does not require very keen powers of observation to determine its existence.

Ringbone may be unilateral, or bilateral, and, if the latter, in but a slight degree; herein lies the difficulty of decision.

Many horses are coarse in this region, still further complicating affairs.

Comparison, by sense of touch with the same hand, is probably the best guide.

In all cases the benefit of the doubt should be given - in fairness to the horse - to the seller.

It must be borne in mind that ostitis and periostitis in the phalangeal region exist in varying degrees of intensity, and that the legacy of this inflammatory 
action may be slight, circumscribed, or extensive.

\section{I9. -THE CORONET.}

No difficulty is likely to confront the examiner over the coronary band.

\section{Coronitis. --}

Quitter.--There may be obvious signs of the present or past existence of this. To be on the safe side, reject.

\section{0.-THE HORNY WALL.}

Sandcrack. - That a sandcrack constitutes unsoundness should go without saying. Its situation is, of course, usually at the quarters (fore limbs) but occasionally in the front, or in both situations. Always lift the hair well off the coronet, otherwise the initial stages of a sandcrack are liable to be overlooked in hind feet at toe. 
It is quite possible for a horse to be "apparently" free from sandcrack at the time of examination, yet on the following day, or in less time, to present the beginning of one. No blame could be laid to the examiner under these circumstances, as it is more than probable that some sandcracks start from within the hoof, extending through it to without.

False Quarter. - Predisposes to sandcrack. Reject.

Keratoma.-Arises from within and at the toe. Not diagnosable until a bulging at the latter.

Rings of Laminitis.

Malformations of the Wall.

Seedy Toe.

Canker extending to Wall. Contraction of the Hoof.

For all of those reject. 
SOUND AND UNSOUND HORSES

\section{SIDEBONE.}

Why there should be difference of opinion as to whether a certain horse has or has not sidebone, is not easy to conceive, but diversity of opinion is of daily occurrence. Doubtless, this confusion often arises through the want of a thorough examination-or as far as practicable - of the part.

This manipulation of the lateral cartilages should take place not only when the horse is standing upon the limb, but also whilst the foot is supported.

It is hardly necessary to say that sidebone is largely confined to heavy horses and vanners of the heavier type, but by no means uncommon in roadsters and hacks.

Veterinary surgeons are fairly unanimous in rejecting these light horses when they have the slightest suspicion of the disease, and rightly so. 
It does not follow that such animals will go lame, the writer having known of several-one with huge sidebonesthat never showed the slightest signs of lameness, neither had they ever done so, so far as known.

Many practitioners are in the habit of passing cart horses with sidebone as sound, provided that the feet are good and well open at the heels.

This is probably the outcome of the fact that so many heavy horses are affected with it, and that one would have trouble in getting a suitable animal without sidebone.

If there are plenty of good horses with sidebone, it is equally true that there are plenty without. The size o a sidebone is no criterion as to whether it will produce lameness.

Huge sidebones are frequently (apparently) quite harmless.

There can be no doubt that there is a 
natural tendency for the lateral cartilages to undergo calcification, more especially with heavy work, increasing age, and hard roads.

Locality has nothing to do with the production of sidebone, unless it be from the nature of the ground, street paving, etc.

Many young horses, absolutely free from sidebone, after working on hard roads, are not very long before showing evidence of it. The chief objection to passing a horse with sidebone as "sound," is the difficulty one has in saying how long it will remain so. At the best, opinion is speculative. With the client not much trouble is likely to arise, because no man could come forward and prove that the animal had the disease (after a period of say, three weeks), at the time of examination.

There is no data as to the length of time that it takes for a lateral carti- 
lage to undergo its degenerative change.

In common fairness to buyer and seller, and as a protective measure for the examiner, it is, in the author's opinion, advisable to reject the horse, passing him as sound in other respects, explaining the nature of the defect to the client. If the latter can get a slight reduction in the price, so much to his advantage.

One or more of the cartilages may be affected, and in rarer instances, those of the hind limbs. In the latter case, their significance is small.

Indurated Cartilages.-By some this is spoken of as incipient sidebone. There is some doubt as to whether this is the right term to apply. Indurated cartilages are not at all uncommon, and more frequently met with in light horses than sidebone, and in two instances coming under the writer's notice were " apparently" the cause of lameness.

We use the term "apparently," be- 
cause no other cause could be ascribed. The cartilage feels prominent, yet has not lost its elasticity. Whether this condition passes on to sidebone does not seem to have been satisfactorily demonstrated. If the animal is not lame and the cartilage in the foregoing condition, one is hardly warranted in rejecting it.

Navicularthritis. - The gravity of the disease renders remarks needless.

\section{I.-SOLAR REGION.}

\section{Canker.}

\section{Flat Sole.}

Thrush.-If slight, defer examination till cured, but for severe thrush, reject. When a client purchases a horse as "sound," he is not expected to begin doctoring its feet as soon as he gets it home. Severe thrush of the cleft has, within the writer's experience, produced very severe lameness.

\section{All Other Diseases of Sole.}


SOUND AND UNSOUND HORSES

\section{2.-COSTAL \& STERNAL REGIONS.}

Fracture of Ribs. Sternal Fistula.

\section{3. - ABDOMINAL AND INGUINAL REGIONS.}

Umbilical Hernia.-This is common enough in foals and colts. Usually undergoes spontaneous reduction. Is unimportant as a rule.

Papillomata - Not of much importance unless very numerous, but client must be consulted.

Scrotal Hernia.-No matter however small, condemn the animal.

Cryptorchidism. - If discoverable, reject.

Enlargement of Superfical In= guinal Glands. - In all probability this will be the result of several attacks of lymphangitis, so that one must not pass the horse as sound. 
The sarne remark applies to the brachial region.

Diseases of the Male and Female Generative Organs. - Any unnatural discharge from these organs is sufficient ground for rejecting.

\section{4.- GLUTEAL REGION.}

Not much to be looked for in this region so far as examination goes.

Compare the quarters (atrophy).

\section{5.-TIBIAL REGION.}

Seldom anything here.

\section{6.-TARSAL REGION.}

We have again arrived at the seat over which many heated arguments have arisen, and are likely to continue to do so-the hock, the troublesome hock.

Of course, the tarsus is a very important part, and if diseased, may 
become exceedingly detrimental to the utility of the animal.

Too much attention cannot be paid to action and conformation.

Sometimes one hock is normally larger than its fellow, though not necessarily diseased.

Thoropin - The presence of this constitutes unsoundness, yet it is an uncommon cause of lameness.

Unless unsightly, there is no reason why the client should not be advised to purchase straight hocks are looked upon, by some, as a predisposing factor in its production.

There should be no difficuly in detecting its presence, denoted by the appearance of a swelling on the side opposite to that on which pressure by the fingers is exercised.

Capped Hock.-Professional opinions are divided as to whether a horse having capped hock should be passed as a 
sound animal. The author is inclined to look upon capped hock as more of the nature of a "blemish" than that of unsoundness, unless there be heat, pain, or lameness present. When confined to the skin or connective tissue subjacent to it, there is no likelihood of the last named, but if the bursa, or point of os calcis be injured, the circumstances are entirely different.

The examiner must judge for himself as to the existence of these conditions.

Spavin. - That the existence of bonespavin upon any horse constitutes unsoundness, there cannot be much doubt.

It is to give "proof" of the existence of spavin upon a given animal that causes so much trouble. It is common amongst all classes of horses, from the Clydesdale down to the tiny Sheltie. Its presence, in a horse required for fast work, is of much greater significance than one performing slow labour, and 
this fact should be borne in mind when advising a client as to whether he might safely venture to purchase.

A large number of veterinary surgeons are in the habit of passing as practically sound cart horses over five years, with good substantial hocks, and free from lameness.

Not a few believe that a spavined hock is "strengthened" and as good as or even better than one free from it.

The size of a spavin bears no relationship to lameness.

Many horses having huge spavins never show the slightest sign of giving way, whereas others having a trifling enlargement are incurably lame. With the former it is fair to assume that the inflammatory deposit has been reparative, and in the latter a destructive inflammation.

Some practical veterinary surgeons pay attention to the position of the 
bony growth. The so-called "occult spavin " is an inflammatory process invading the small tarsal bones without any obvious sign of enlargement.

The best method of detecting spavin is by comparing both hocks with the fingers of the same hand; in this way the least difference in size can be told. View the hocks in profile, standing in front of the haunches. Any enlargement will be seen. If spavined, reject.

Sprung Hock. - General enlargement of hock, spoiling its true action. Reject.

\section{Bursal Enlargements.}

Psoriasis.-Reject, as it is often a very troublesome and unsightly disease.

Curb. - Whether small or large, this can be readily seen in profile. Some horses are very lame from its presence, others it never touches. The safest and the right plan is to reject the animal. The client can then please himself as to 
purchasing. All classes of horses are liable to become affected with curb.

\section{7.-METATARSAL RF.GION.}

\section{Temporary or Permanent En=} largement of Cannon.-In the former case defer examination, and in the latter reject the animal.

\section{8.-PHALANGEAL AND PEDAL REGIONS.}

Brushing.-When forming an opinion regarding this, the examiner must pay particular attention to the direction of the feet, and whether the horse is "green." A horse at regular work, and shod with the so-called "preventer" shoe, bruising his fetlocks, should most certainly be condemned.

Bursal Enlargements.

Ringbone : Sandcrack (toe); Canker, Thrush, etc., etc., as in the forelimbs. 
SOUND AND UNSOUND HORSES

Reject for-

Chronic Cough.

Broken Wind.

Shivering.

Stringhalt.

Repeated Colic.

Vertigo.

Eczema.

Mange.

Intermittent Pulse.

General Unthriftiness. etc. 


\section{CHAPTER VIII}

\section{METHODICAL EXAMINATION}

No matter however experienced the veterinarian may be in the examination of horses as to soundness, more errors of judgment are sure to be committed than by one whose strict observance of method is rigidly adhered to.

If a client asks for a professional opinion upon a certain region in relation to its soundness or otherwise, this is a different matter.

One of the worst faults a student can cultivate is that of slip-shod examinations when examining re soundness.

$$
16+
$$


Every square inch of the external anatomy ought to be gone over, and a regular "point to point" system observed. Not one of the most agreeable experiences is that of having a client "soured" because he brought a horse to be examined before purchasing, and that Mr. So and So " passed him sound," within a week of which he becomes idle and useless, owing to some infirmity, existing at the time of examination, and patent to any professional observer's eye, but evidently overlooked by the examiner through a too superficial examination.

- Experienced buyers of horses usually confine their examination to the age of the animal, to his action, build, and manipulation of the back tendons, lateral cartilages (outer sides only as a rule) and hocks-(spavin, curb or thoropin).

The question may be asked, How

$$
165
$$


often do these buyers get their fingers burnt?

In the author's experience, very frequently indeed. If dealers, some other "innocent" client is asked to bring in his share of the salve to heal the burn. The writer does not mean the reader to understand that because " method" be adopted, mistakes will never occur, because they will, no matter however careful or methodical the examiner may be; but that these errors of judgment will be the exception, rather than the rule.

It is through an absence of system where the non-professional fails, and it is the business and duty of the M.R.C.V.S. to protect such from this failing.

When examining horses at fairs, the facilities for thorough examination may not seem so favourable. This difficulty can easily be overcome. If a client 
accompanies one to some particular fair or fairs with a view to purchasing, the best plan is that of allowing him to select the horse of his choice, give it a superficial look over, and if this is satisfactory - the experienced examiner can glean a great deal even in this way - get the seller to lead the animal into some quiet corner, away from the bustle, and then examine methodically.

When purchasing at a fair, advise a client, whenever possible, to deal with such men as have a reputation to sustain, and with whom better terms can be arranged. A veterinary surgeon is often asked to accompany a client to some horse repository, where the conditions for examination are sometimes not much better than at a fair ; though the purchaser may have better facilities of knowing what sort of a (bargain) purchase he has got, and if returned within the specified time, his money is in safe 
custody. At public auction (without a reserve, of course), the highest bidder is necessarily the buyer, and the auctioneer must deliver the animal to the buyer after the money has been paid. There is no further liability on the part of the purchaser, but the vendor may still be held responsible, in accordance with the conditions relative to the merits of the animal.

Three or four days, as a rule, is the time allowed for the return of the horse to the auctioneer. When a horse is warranted quiet to ride, drive, etc., and catalogued as such. but on trial proves to be vicious, it can, of course, be returned, false representation rendering the sale void.

Selling under a false name also renders the contract worthless : hence there are certain advantages of buying at a repository not obtainable under many other circumstances. 
When a horse is brought to the veterinary surgeon's premises for examination, if the feet are muddy, they should be washed, and the animal then put into the stable say from half to one hour, so as to allow it to cool down.

Whilst in the stall, many faults are capable of detection. The "double" expiratory effort characteristic of broken wind, should always be looked for.

The chief of these are-

Crib Biting.

Weaving.

Pointing of the Foot.

Shivering.

Wind Sucking.

Kicking.

Biting.

Quidding of Food.

Broken Wind.

Difficulty of deglutition can be noted if a drink of water is given. Shivering 


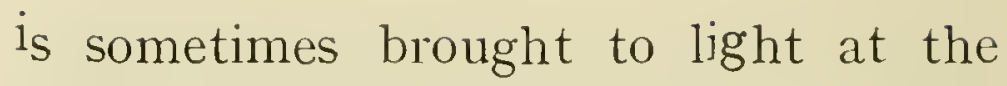
same time. As soon as cooled down, the temperature ought to be taken, and if found to be much beyond normal, the further examination of the animal should preferably-though not necessarily-be deferred for a few days.

Directly the horse is brought out of the stable, have him trotted on hard-harder the better-ground, and take special notice of "action," both fore and aft. If there is any doubt as to the presence of lameness, defer the examination until thoroughly satisfied that such no longer exists.

Rest, for a reasonable length of time does, after a fair journey, show the lameness arising through navicularthritis as a rule.

Defective action should also be duly noted, bearing in mind the short step so characteristic of the disease last named. Now have the horse put on level ground, 
so as to get him to stand squarely, and apply the test of keen observation all over him, noting the pros and cons of a well built horse.

Strictly speaking, we must regard the animal as being bi-symmetrical for examination purposes, and carry it out on these lines.

Measure the height, and make a note of this. The best standards are those having a spirit level, and only these should be used where exactness - as at exhibitions-is required. Never measure a horse on sloping ground, and never allow the seller-more especially a dealer - to stand the horse on selected measuring ground.

It is not a difficult matter to make a I6-hand horse out of a I5, or convert (apparently so) the former into the latter. It is frequently done. Begin the examination in every instance on the near side and finish this before pro- 
ceeding to the right, unless it be for purpose of comparison.

Examine the nasal cavity as high up as possible. Note whether dry or moist schneiderian membrane. Next the age, and at the same time see whether the edges of the incisors are worn (cribbing).

Withdraw the tongue, examine the surface, and inspect the angles of the mouth for thickening or scarring - the result of "pulling." The molars at this stage also call for inspection. Pecuss the frontal and maxillary sinuses, comparing any dulness with the corresponding cavities.

Inspect the eye as far as possible at this stage. With the right hand examine the intermaxillary space and sides of the jaw for swelling, fulness, fistula, etc. The larynx may be "lightly" pressed, noting the character 
of the cough, if slight pressure has induced it.

With the left hand examine the poll and then the cavity of the left ear, likewise the parotid gland.

The jugular vein should be raised with the fingers of the same hand. Look for venesection scar. If a doublemaned horse, examine the upper border of the neck, throwing the mane to rest on the off side.

This brings us to the root of the neck, and to the withers, "old" or recent scars in either of these regions being noted and given their full significance, or otherwise. White or different coloured hair points to an old injury. Compare the left with the right shoulder for evidence of paralysis of the supra-scapular nerve (shoulder slip). Pass the hand (right) over the arm until the top of the forearm is reached, at the same 
time noting whether the elbow is all sound.

The examination of the pectoral limb must be carried out by regarding it, from the forearm to the coronet, as having anterior, posterior, inner and outer surfaces.

Begin with the anterior and glide the right hand over the forearm (sprain, etc.), until the carpus is reached. Draw the limb forwards and carefully inspect the skin of the knee (blemishes and broken knee), feel the sub-cutaneous tissue for thickening, or for any distension of the carpal sheaths.

Continue this examination over the metacarpus-noting whether there be an exostosis, blemish, etc.-go over the fetlock (ringbone) to the coronet, remembering that a sandcrack at the top and front of a "fore" hoof is not uncommonly met with, though usually at the quarters. Now 
examine the inner face from above to below. It is not usual to find much wrong on the inner face of the forearm, nor yet on this surface of the carpus, but the metacarpus frequently has a variously sized exostosis (splint) upon it.

Just below the knee, this surface also requires carefully inspecting for "scarring," the result of speedy cutting. Compare the inner surfaces of the fetlocks, and examine the hoof for sandcrack on its " inner" quarter.

Outer Face.-The forearm here again does not require much attention, neither does the carpus, but the metacarpus may present one or more growths for one's consideration, and the hoof a sandcrack on its "outer" quarters, or a false quarter. The posterior surface demands the most attention.

Not as a rule much on the forearm, excepting at the back of the elbow- 
capped elbow - and the inner side of it for scarring after median neurotomy. When the carpus is reached, the joint should be flexed by grasping the forearm and cannon. The hoof should be capable of being brought almost up to the point of the elbow. Psoriasis frequently appears in the bend of the knee. Whilst the leg is off the ground, thoroughly manipulate the top (carpometacarpus) of the metacarpal bones for "knee splints." These are easily overlooked unless the fingers are well pushed under the tendons. (The prefix "incipient" is sometimes applied to a splint when in the formative stage.) Scarring also results after the removal of a splint.

Sprain of the check ligament may be found, also thoropin of the knee. Examine the channel formed by the metacarpals for splint over its whole length, for old or recent sprains of the 
flexors, or suspensory ligament, and for tenotomy marks. Flex the fetlock and examine it for signs of wear, thickening, etc. Carefully inspect the seat of neurotomy.

The foot being still held up, examine the hollow of the heel, cleft of the footpad, size, etc., of the latter, sole and "inner" and "outer" lateral cartilages. Also examine these when the foot is on the ground, and note whether indurated (incipient sidebone) or whether calcified. Always examine the lateral cartilages, no matter what be the class of horse you are examining. Compare the size of the feet and note the angles at the toe and heels. All that now remains to be done is the removal of the shoe, and this may conveniently be deferred until the further examination of the limbs and body has been completed.

Working the hand up from the 
posterior angle of the scapula, the withers require careful inspection, and then come down to the girthing place (girth galls).

The ribs and back (broken ribs, sarcoma, sore back) and the loins for anchylosis, by bending the horse. If a young animal, inspect the umbilicus for hernia.

The left hand should glide over the quarter to the tail, which ought to be raised to expose the anal aperture. (Morbid growths, dilatation, etc.).

When raising the tail, bear in mind the resistance offered is generally a measure of the animal's vigour.

A feeble dock denotes, as a rule, a correspondingly weak state of the skeletal muscles generally.

If necessary, have a fore limb held up, and compare the angles of the croup and haunches, and note whether there is any wasting of muscle over the quarters or thighs, an old fracture, etc. 
If an entire, examine the generative organs as far as practicable, and note whether any obvious scrotal hernia exists. If a gelding, look for the presence of both scars on scrotal sac, as the best possible-though not positiveevidence of castration having been duly performed. Likewise examine for swelling of sheath, or morbid growths.

Whilst in the inguinal region, inspect the inner surfaces of thighs for evidence of chronic lymphangitis; specific, or nonspecific sores.

The right hand now glides down the front of the tibia until the hock is reached: its inner face likewise examined, and then the posterior up to the os calcis.

Thoropin and capped hock will, if present, be seen or felt.

In the bend of the hock psoriasis may occur. The so-called sprung hock is a 
general enlargement of the whole of the tarsus.

The fore limb should be held up, and the hocks compared for the presence or absence of bone spavin.

It is not a bad plan to measure their girth over the seat of this exostosis.

Any difference in size should be taken into account when weighing up the results of the examination. The socalled "blood-spavin" is not an unsoundness (a prominent part of the vena-saphena), and how in the name of all that is rational any veterinary surgeon can reject a horse for such a thing is more than the author's intelligence enables him to comprehend.

The term "occult spavin " is applied to hock lameness, arising out of an inflammatory (ostititis and persostitis) action going on between the tarsal bones. "Incipient" to a commencing spavin. Bog spavin is applicable to 
any puffy condition of the hock-inflammatory, or non-inflammatory. Flex the hock, keep it flexed for half a minute, and then make the horse stand over so as to throw sudden weight on to the tested hock.

A weak hock can often be detected in this way. The hand glides down the inner and front face of the metatarsus until the fetlock is reached. In young animals exostoses are not uncommon here. Knuckling over is frequently met with. Then over the pastern to the coronet and hoof.

Ringbone; evidence of brushing; bruised fetlock (induration of skin), sandcrack, or bruised coronet. The outer and posterior surfaces from the os calcis next require examining.

Curb : chronic thickening of the back tendons, or for evidence of tenotomy found.

Examine from below the fetlock on 
the posterior surface for ringbone, cracked heels, contracted heels, sidebone, thrush, and for a diseased frog. This, which for the sake of convenience, the author calls the "general" examination, completes the work on the near side, and should be followed by its repetition on the "off" side. Proceed to the "special," which comprises :-

I.-The removal of the fore (preferably all) shoes so as to facilitate an examination of the sole and its junction with the wall.

Pare out the seat (inner) of corn, and the outer heel also. Note the condition of the sole, whether flat, convex or normal. Look for seedy toe, thin sole, etc. Observe the form of shoe and its wear.

Have the shoes nailed on again and proceed to-

2.-The examination of the eyes in a darkened loose box by means of the 
catoptric test as a "general " one, and with theophthalmoscope for a "special," if required. Bear in mind that three images should be seen (in the normal eye), two erect, moving in the same direction as the candle, and the third an inverted one, moving in a diametrically opposite direction.

In cataract, the third image is either very indistinct, or else absent. It is a very good plan to dilate the pupil with sol atropine sulph. (4 grains to ounce).

3.-Back and bend the horse sharply, so as to try and make him show-if present-stringhalt or chorea.

4.-Test his respiratory and circulatory apparatus.

To merely "grunt" a horse is insufficient. Many roarers do not grunt when a feint is made to strike them. It is useful in its way, but does not afford one positive evidence.

Take the pulse whilst the horse is 
at rest, and note its fulness and regularity.

If a horse has not a sound heart he will not be sound in his wind.

Many horses appear very distressed when tested for their wind, but it does not follow that there is any defect in the laryngeal apparatus. If a saddle horse or roadster, it can be galloped, but better results are obtained by strapping up the near fore leg with a Rarey's leg strap. Put on a pair of knee caps and longe the horse in a circle for five or ten minutes behind a whip. If there is ought wrong with his wind or heart this test will find it out.

Cart horses should be circled with a longeing rein at a trot for a few minutes (no leg strap), or made to pull a load up a steep incline.

This completes the examination, and notes should have been made as to what has been found, the names and addresses 
of both seller and buyer, the name of the horse, its sex, colour and markings, and the certificate then written, if such be given.

Some practitioners, when they find a horse unsound, give no certificate-others do so. It is more a matter of choice.

The terms " practically" or "usefully" sound are often employed, and there is no doubt they are useful "prefixes."

In the author's opinion it is a good plan-and a very safe one-to write the certificate, indicate the causes of unsoundness, and add a rider such as " in all other respects the animal is sound."

Another matter to bear in mind, and one which many veterinarians adopt, and that is of having a footnote on their certificates to this effect -

"This opinion is given on the best 
SOUND AND UNSOUND HORSES

of my judgment, but I do not hold myself in any way responsible."

To some extent this is true, because it is quite beyond any man to have knowledge, without previous acquaintance, that a particular animal is effected with epilepsy, megrims, frequent colic, or other obscure malady. 
SOUND AND UNSOUND HORSES

Example OF Veterinary CERTifiCATE.

EXAMINATION AS TO SOUND. NESS.

To-day, at the request of .............

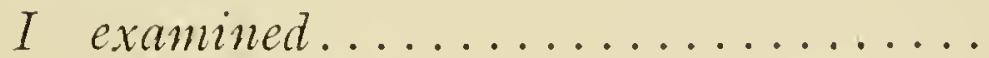
Animal Age Sex Height Colour

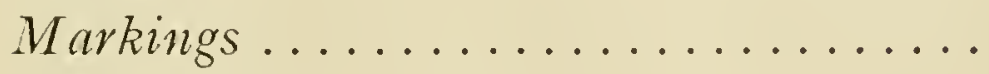

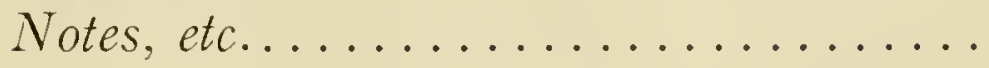

In my opinion said animal is ....... (Signed) 


\section{CHAPTER IX}

\section{LAW IN RELATION TO WAR= RANTY OF HORSES.}

A WARRANTY implies all faults both known and unknown to the vendor, and a breach of this entitles the vendee to recover. A distinction must be made. however, between warranty and falsenot fraudulent-representation.

Let us assume that an intending purchaser goes to some fair, market, etc., and there buys a horse at a moderate price. but which subsequently turns out 
to be a "roarer," etc. The buyer is unable to recover, whilst the seller is perfectly free from the law of fraud.

A warranty may be either verbal or written, preferably the latter, in which the abode of the seller, date, assurance, and attested signature, are clearly set forth thereon.

The mere fact of having given a big price for a horse does not, in law, imply warranty as to soundness. This contrary view of the law of warranty has long since exploded.

Warranties are frequently given for a limited period. Such are binding in accordance with the time specified. A warranty states that :-

"If at the time of sale the horse has any disease which either actually does diminish the natural usefulness of the animal so as to make him less capable of work of any description, or which in its ordinary pro- 
gress will diminish the natural usefulness of the animal, or if the horse has either from disease, whether such disease be congenital or arises subsequently to its birth, or from accident, undergone any alteration of structure that either actually does at the time or in its ordinary effects will diminish the natural usefulness of the horse, such a horse is unsound."

Horses are frequently catalogued as being quiet to ride or drive, but this warranty does not necessarily imply freedom from vice. It is a warranty expressive of certain qualities, beyond which the horse has many defects and vices.

A buyer can recover provided there has been an express warranty or proof of fraudulent intention.

A warranty given by a servant in the employment of a private person, with- 
out the consent of his master, or agent acting on behalf of the latter, is not valid, but a warranty given by a servant whose master or masters trade in horses, renders the contract binding, hence liability.

Horses are frequently offered for sale "With all faults." The aim of this is at once obvious, but ambiguous so far as the animal's defects, etc., are concerned.

No person would, we anticipate, be foolish enough to enter into litigation regarding an animal purchased "with all faults.'

In England, on the principle of caveat emptor (let the buyer beware), the seller is not liable for latent defects, unless there be fraud on his part, or unless he has expressly warranted the horse. The law of Scotland in relation to this matter, is assimilated to that of England. 
When a horse has been sold "with all faults," the seller renders himself liable if he has used artificial means of disguising any defects, or defects which would otherwise have been patent to the buyer's observation, e.g., stopping a sandcrack, or filling up a false quarter.

If the vendor gives a warranty of a horse having patent defects, and has pointed these out to the buyer, the warranty holds.

Whenever the seller gives a general warranty, with the exception of some patent defect, e.g., splint. curb, etc., it is absolutely essential that he safeguards himself by drawing attention to such in writing, not orally.

A general warranty seems to comprehend all diseases of an organic nature.

Crib-biting and wind-sucking, though vices, should, we consider, come within 
the meaning of unsoundness, or better still, unfitness.

Horses are frequently warranted sound and free from vice.

It has been held in England that a seller's general warranty was not contravened when the buyer found out that the animal's age was over that stated in the pedigree, because the vendor showed that it was so stated in the pedigree which he received when he purchased the horse, and that he had no reason for supposing that such was untrue. We will not say "that the seller had no other means for ascertaining the correct age of the horse."

If the seller of a horse refuses to take the animal back again after the buyer fincls that the warranty has been or believes it to have been contravened, the horse should be placed in neutral custody. If the seller uses a horse thus 
returned to him, he is barred from suing for the price.

Whilst a verbal warranty is binding. there may be a great difficulty in establishing the fact that the vendor gave such warranty at the time of sale. Hence the necessity of having a witness in support thereof, or, what is still better, a written warranty, taking care that the wording of such leaves no loopholes.

If a dealer, etc, allows a horse to go on trial to the intending buyer and an injury or death occurs whilst the latter is custodian, the hirer or party with whom the horse is on trial must show that he is in no way responsible for such damage. It is reasonable to assume that the party to whom a horse has gone on trial, or hire, could not be held liable for any damage to the same, when such arose through causes over which the hirer, etc., or person in charge had 
not, or could not have had control.

For convenience, we will suppose that the custodian or his servant, is either riding or driving the animal along an ordinary thoroughfare, apparently free from influences likely to disturb the animal's temperament. Without warning, something comes upon the scene, causes the horse to shy, perhaps falling upon its knees, and blemishing the latter, for which the proprietor seeks reparation. Under these circumstances we are of opinion that the onus could not be held to rest with the hirer.

In this case, depreciation of property may have occurred, over which the custodian had no control.

In law there is a distinction as to the degree of neglect; a gratuitous borrower being responsible for slight negligence, whereas the hirer is only responsible when it can be shown that there has been ordinary negligence. 
If several persons fraudulently endeavour to sell a horse, knowingly unsound, yet represent such as sound to the purchaser, they render themselves liable to criminal prosecution.

Where there is a contract to supply a horse answering to some particular description, and the buyer has not had an opportunity of seeing or trying the animal, the latter must conform to the specifications of the contract, otherwise the contract is voidable, the principles of caveat emptor being, under these circumstances, inapplicable.

Every affirmation at the time of sale of a horse is a warranty.

In England, the sale of goods in market overt (i.e., a public place), although such may not be the property of the seller (stolen articles) renders the contract safe, the buyer being able to retain his purchase. For instance, a man might steal a horse. sell it in the market. 
yet the buyer's contract holds valid. In years gone by horse stealing was pretty common. With the aim of suppressing horse theft, statutory restrictions were passed during the reign of Philip and Mary, and Elizabeth.

These Acts provided :-

"That a horse shall be openly exposed in the time of such fair or market for one whole hour together, between ten in the morning and sunset, in the public place used for such sales, and not in any private yard, stable, etc., and afterwards brought to the book-keeper by the vendor and vendee for toll to be paid, if due ; if not, a penny must be given to the book-keeper. The latter must make entry of the price, colour. recognition marks, together with the names, additions, and abodes of the buyer and seller. The seller's name, address, etc., must 
be attested. Such sale shall not take away the property of the owner if within a period of six months after the theft of the horse, the lawful owner puts his claim before the Magistrate residing in the district where the animal shall have been found, and within forty days more, prove, on oath of two witnesses, that the horse is his property, tendering to the party in possession the price which bona fide. he paid for the animal in market overt. If any of the aforesaid points be neglected, the sale is void; the owner (purchaser) shall still retain his property, which he may seize or raise action for the restitution of such in the event of its being seduced from his control."

In Scotland the matter is different. The proprietor of a stolen horse (goods) could reclaim it from the buyer, pro- 
vided that such had been sold by the person committing the theft.

The second sale with delivery is effectual against the'first sale without delivery.

Trading on Sunday.-In England the Sunday Observance Act was introduced during the reign of Charles II. for the purpose of preirenting tradesmen exercising their calling on the Lord's Day. By the wording of this Act, it is illegal for a horse dealer, cattle dealer, etc., to sell his stock upon Sunday. Any sale completed on Sunday can be rendered void.

It is quite lawful for discussion to take place regarding the purchase of any animal upon the day named, but the contract must not be completed on the aforesaid day.

A private party - one not exercising his own calling-can transact business 
on Sunday, and the contract can be held valid.

Regarding Sunday trading of any description, the author is strongly in favour of its discouragement, whilst the want of necessity renders it still further objectionable.

Several statutes of the Scottish Parliaments enjoin the due observance of Sunday. The Act I66I prohibits the " using any sorts of merchandise on the said day, and all other profanation thereof whatsoever," under the penalty of $E$ Io Scots for every ordinary offence.

The voluntary acts of private persons are binding though dated on Sunday.

Agents.-An auctioneer is legally bound to take every possible care of animals entrusted to him for the purpose of sale. Discase or injury arising whilst in his care. places the onus on him to show that such arose without ordinary negligence. 
As carriers of live animals, a railway company must take all reasonable precautions, but is not liable for damage from wholly unusual or unexpected causes, e.g., injury from some inherent vice of the animal. The liability of railway companies is restricted to $f 50$ for a horse (ox, $\mathrm{E}_{5} 5$; sheep and pigs, $f^{2}$ ), unless the value has been declared at the time of booking, and the extra charge for such paid.

Both in England and Scotland, innkeepers, stablers and road carriers, are liable for animals entrusted to their care. The proprietor of such is liable for damage arising out of negligence of his servants.

Carriers are not responsible for losses arising from the act of God (e.g., lightning stroke to a horse whilst being conreved home).

A person who holds himself out to perform, for hire, the duties of carrier, 
incurs an universal responsibility.

A carrier's liability as such ceases if the consignee cannot be found, refuses or delays to take delivery, though of course he is still obliged to take proper care of the animal, until an arrangement has been made.

Horse stolen from carriers render the carriers liable; but any kind of stock put into a farmer's hands for grazing purposes, should such be stolen, unless clearly the outcome of neglect, e.g.. broken down fencing, hedges or gates left unfastened, renders the farmer free from liability. 


\section{CHAPTER X}

\section{SALE OF HORSES}

SALE is a mutual contract batween the vendor and vendee, or purchaser, by which the property or ownership of the seller in the horse, or other subject of sale is transferred to the buyer, in consideration of the price. Delivery of the horse and payment of the price may be made simultaneously . on completion of the contract of sale, or one or the other may be deferred to a later date; but neither the delivery nor the payment of the price are necessary for the completion of the contract. 
Delivery and payment are the reciprocal obligations of the vendor and vendee under a completed contract of sale, and failure to deliver on the one hand, or to make payment on the other, renders the vendor or vendee liable in action at law.

The Sale of Goods Act, I893, save in some minor details, assimilates the laws of England and Scotland with regard to the sale of goods, which includes horses. By the provisions of that Act the property or ownership in the subject of sale is transferred at such time as the vendor and vendee intend it to be transferred, and such intention must be gathered in the absence of express stipulation from the terms of the contract, the conduct of the parties, and the circumstances of the case; but, unless it is otherwise apparent, in an unconditional contract of sale. the property passes at the time of the sale. When a horse is delivered to a purchaser 
"on approval," or " on sale or return," or on any other similar terms, the property passes to the vendee as soon as he signifies his approval, or adopts the transaction by treating the horse as absolutely his own, or on expiration of the appointed time; and if there be no time fixed, then of a reasonable time without returning the horse, or giving notice of his disproval or rejection of it. It is important to determine when the property has passed from the vendor to the vendee, because from that time the horse becomes the property of the latter, and is at his risk, although it still may be in the custody of the vendor. The vendor in these circumstances becomes the custodian of the animal, and is liable for the negligence of himself or his servants. In order to establish the sale of a horse in England, the purchaser must have accepted delivery, or if delivery is to be delayed, then some- 
thing must be given in earnest, to bind the bargain or in part payment; or failing earnest or part payment a note or memorandum of the sale must be made out, and be signed by the purchaser, or by his duly authorised agent. The acceptance of the horse will be determined in the absence of express stipulation by the rules laid down in the Sale of Goods Act already referred to. Earnest is of two kinds, symbolical and pecuniary, and anything, such as a saddle or a bridle, may be used for the purpose of the former, while the latter is a sum of money. The note or memorandum of the sale need not be in any particular form, it being sufficient to show, in connection with the surrounding circumstances, that it refers to the contract of sale between the vendor and the vendee. In order to leave no room for doubt, it should, however, state as plainly as possible (I) the seller, giving 
his fuli name and address ; (2) the purchaser's full name and address ; (3) the particular horse sold; (4) the price ; and (5) the time of delivery. There is no stamp required for this memorandum according to the present law. In Scotland no such formalities are necessary to constitute a contract of sale for future delivery. If the seller agrees to sell, and the purchaser agrees to purchase a particular horse at a specified price, the contract is complete. In the event of the horse being disconform to the contract, either through breach of warranty or in any other respect, formerly in Scotland, the purchaser was bound at once to inform the vendor, and to reject the horse, which was usually done by returning it to the vendor, or placing it in neutral custody. A purchaser in Scotland has still this remedy; but by the Sale of Goods Act, he (the purchaser) may, as in England, hold the horse,

$$
207
$$


unless there is a stipulation in the contract of sale allowing him to return it. If the price has been paid, the purchaser on returning the horse can demand and sue for repayment; but if he does not return the horse, he may claim damages from the vendor, being the difference in price between the horse as sold under the contract, and the sum it would realise on being sold in the open market. If the purchaser fails to pay the price and take delivery of the horse, the vendor may give notice to the purchaser and sell the horse again. The purchaser will be liable to the vendor for any loss arising from this sale; but if any profit results from this sale, it will go to the purchaser, on the ground that by the contract of sale the vendor became custodian of the horse on behalf of the purchaser. In Scotland it is usual to apply to the Court for a judicial warrant to sell the unclaimed horse. 


\section{CHAPTER XI}

\section{HORSE SOCIETIES.}

IN England and Scotland numerous organisations have been formed for the purposes of not only encouraging the breeding of horses, but with a view to advancing the standard of the different varieties of horses. For this purpose Stud Books have been compiled, wherein the Registration of Birth, Pedigree, etc., is contained. The following is a list of the more important of these Societies :-

The Shire Horse Society-

Hon. Secretary, I2, Hanover S.q.

Clydesdale Horse Society- -

Secretary, 93, Hope St., Glasgow. 
SOUND AND UNSOUND HORSES

Suffolk Horse Society-

Secretary, Woodbridge, Suffolk.

London Cart Horse Parade SocietySecretary, I2, Hanover Square, London.

The General Stud Book-

(For Thoroughbreds) -

Secretary, Old Burlington Street,

London; also Newmarket.

Yorkshire COACH Horse SocietySecretary, Appleton Roebuck,

Yorkshire.

Cleveland Bay Horse Society-

Secretary, Potto Grange, Northallerton, Yorkshire.

Hunters' Improvement Society-

Secretary, I2, Hanover Square, London.

The Trotting Union of Great

BRITAIN AND IRELAND-

Secretary, 7, Trinity Square, Brixton, London. S.W. 
SOUND AND UNSOUND HORSES

The Hackney Horse SocietySecretary, I2, Hanover Square, London.

Royal Commission on Horse BreedING-

Secretary, 22, Great George Street, Westminster. London, S.W.

Polo Pony Society-

Secretary, Felhampton Court,

Church Stretton.

New Forest Pony Society-

Secretary, Lymington, Hampshire. Shetland Pony Society-

Secretary, 35, Market Street,

Aberdeen.

Any of the foregoing Societies will, on application, furnish any particulars that may be sought relating to the variety of horse for which purposes it has been formed.

Although not really necessary, it is adrisable to enclose a stamped directed envelope when a reply is required.

Loniton: R. A. Everett \& Co., Limited, Fssex Stret Strand. 




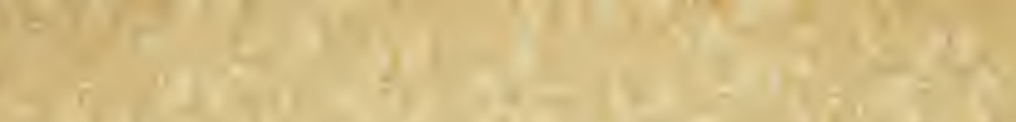

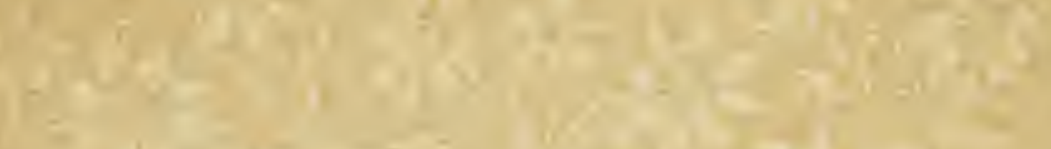

$+2$

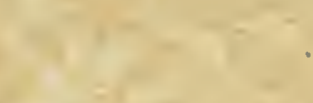

$\cdot$
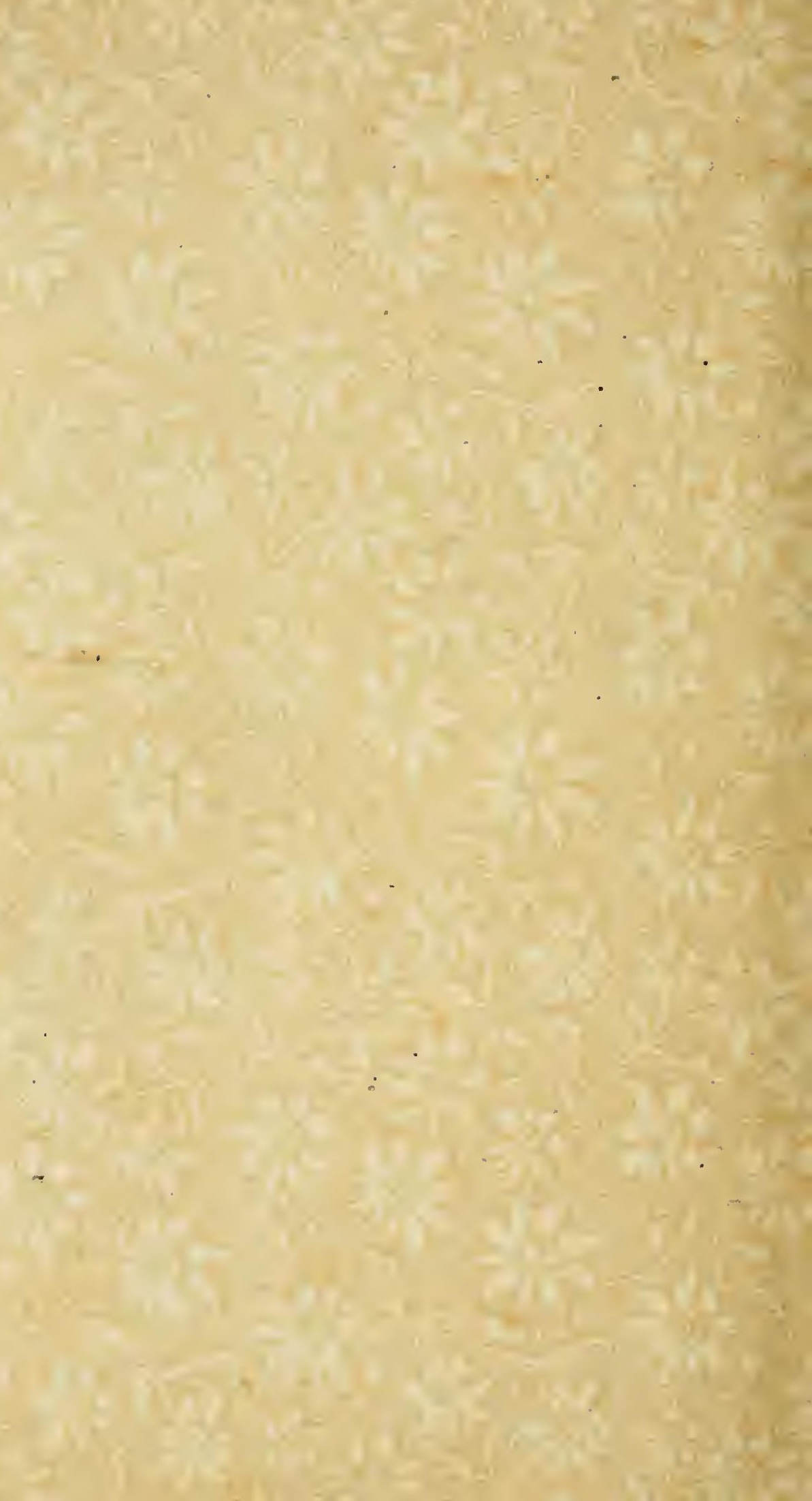

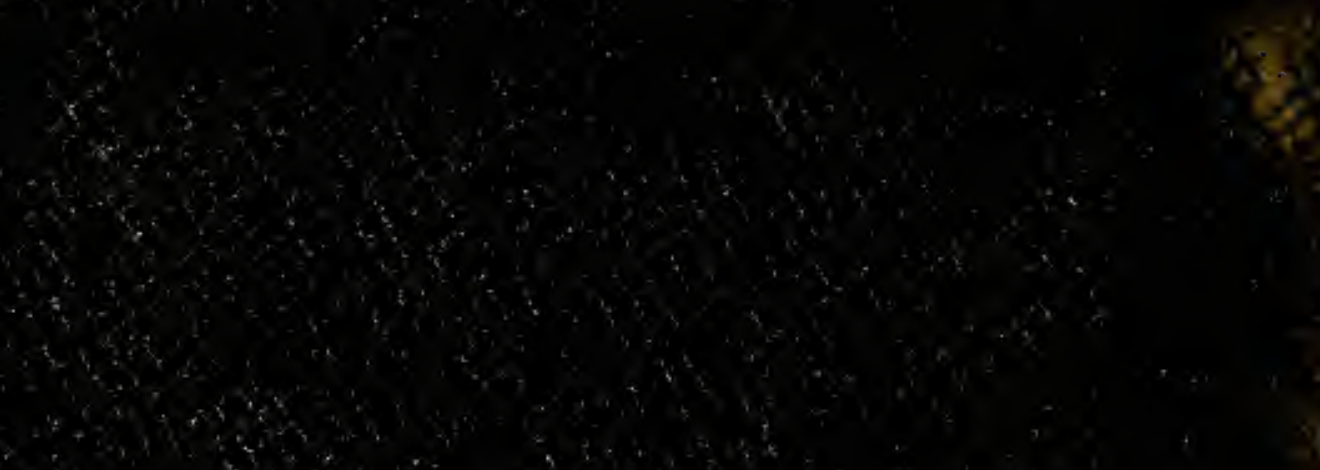

$\Delta x$

5,2

$$
a_{-3}
$$

